\title{
Platonic Relationships in Metal Phosphonate Chemistry: Ionic Metal Phosphonates
}

\author{
Konstantinos Xanthopoulos ${ }^{1}$, Zafeiria Anagnostou ${ }^{1}$, Sophocles Chalkiadakis ${ }^{1}$, \\ Duane Choquesillo-Lazarte ${ }^{2}{ }^{(D}$, Gellert Mezei ${ }^{3}$, Jan K. Zaręba ${ }^{4}{ }^{\mathbb{D}}$, Jerzy Zoń ${ }^{5}$ and \\ Konstantinos D. Demadis ${ }^{1, * \mathbb{D}}$
}

1 Crystal Engineering, Growth and Design Laboratory, Department of Chemistry, University of Crete, Voutes Campus, GR-71003 Crete, Greece; kostas.sharma@gmail.com (K.X.); zaphiri@gmail.com (Z.A.); sophocleschalk@gmail.com (S.C.)

2 Laboratorio de Estudios Cristalográficos, IACT, CSIC-Universidad de Granada, 18100 Granada, Spain; duane.choquesillo@csic.es

3 Department of Chemistry, Western Michigan University, Kalamazoo, MI 49008-5413, USA; gellert.mezei@wmich.edu

4 Advanced Materials Engineering and Modeling Group, Wroclaw University of Science and Technology, Wyb. Wyspiańskiego 27, 50-370 Wrocław, Poland; jan.zareba@pwr.edu.pl

5 Department of Thermodynamics, Theory of Machine and Thermal Systems,

Faculty of Mechanical and Power Engineering, Wroclaw University of Science and Technology, Wyb. Wyspiańskiego 27, 50-370 Wrocław, Poland; jerzy.zon@pwr.edu.pl

* Correspondence: demadis@uoc.gr; Tel.: +30-2810-545051

Received: 15 May 2019; Accepted: 7 June 2019; Published: 11 June 2019

\begin{abstract}
Phosphonate ligands demonstrate strong affinity for metal ions. However, there are several cases where the phosphonate is found non-coordinated to the metal ion. Such compounds could be characterized as salts, since the interactions involved are ionic and hydrogen bonding. In this paper we explore a number of such examples, using divalent metal ions $\left(\mathrm{Mg}^{2+}, \mathrm{Ca}^{2+}, \mathrm{Sr}^{2+}\right.$ and $\left.\mathrm{Ni}^{2+}\right)$ and the phosphonic acids: $p$-aminobenzylphosphonic acid ( $\left.\mathrm{H}_{2} \mathrm{PABPA}\right)$, tetramethylenediamine-tetrakis(methylenephosphonic acid) ( $\left.\mathrm{H}_{8} \mathrm{TDTMP}\right)$, and 1,2-ethylenediphosphonic acid ( $\left.\mathrm{H}_{4} \mathrm{EDPA}\right)$. The compounds isolated and structurally characterized are $\left[\mathrm{Mg}\left(\mathrm{H}_{2} \mathrm{O}\right)_{6}\right] \cdot[\mathrm{HPABPA}]_{2} \cdot 6 \mathrm{H}_{2} \mathrm{O},\left[\mathrm{Ca}\left(\mathrm{H}_{2} \mathrm{O}\right)_{8}\right] \cdot[\mathrm{HPABPA}]_{2},\left[\mathrm{Sr}\left(\mathrm{H}_{2} \mathrm{O}\right)_{8}\right] \cdot[\mathrm{HPABPA}]_{2}$, $\left[\mathrm{Mg}\left(\mathrm{H}_{2} \mathrm{O}\right)_{6}\right] \cdot\left[\mathrm{H}_{6} \mathrm{TDTMP}\right]$, and $\left[\mathrm{Ni}\left(\mathrm{H}_{2} \mathrm{O}\right)_{6}\right] \cdot\left[\mathrm{H}_{2}\right.$ EDPA $] \cdot \mathrm{H}_{2} \mathrm{O}$. Also, the coordination polymer $\left\{\left[\mathrm{Ni}\left(4,4^{\prime} \text {-bpy }\right)\left(\mathrm{H}_{2} \mathrm{O}\right)_{4}\right] \cdot\left[\mathrm{H}_{2} \mathrm{EDPA}\right] \cdot \mathrm{H}_{2} \mathrm{O}\right\}_{\mathrm{n}}$ was synthesized and characterized, which contains a bridging 4,4'-bipyridine (4,4'-bpy) ligand forming an infinite chain with the $\mathrm{Ni}^{2+}$ cations. All these compounds contain the phosphonate anion as the counterion to charge balance the cationic charge originating from the metal cation.
\end{abstract}

Keywords: metal phosphonate; ionic compounds; phosphonic acids; organic salts

\section{Introduction}

The area of metal phosphonate chemistry has seen impressive growth in the last decade [1]. Metal phosphonate compounds are known for their complex and diverse structural motifs [2] and their unique structural topologies [3]. They are also candidates for use in versatile application areas such as proton conductivity [4], gas storage [5], pharmacology [6], ion-exchange [7], catalysis [8] and corrosion inhibition [9].

The phosphonate group, either mono-deprotonated $\left(-\mathrm{PO}_{3} \mathrm{H}^{-}\right)$, or doubly-deprotonated $\left(-\mathrm{PO}_{3}{ }^{2-}\right)$, demonstrates high affinity for metal ions [10]. Because of this, and the stability of the metal phosphonate coordination bonds, hybrid metal organic materials with non-coordinated phosphonate groups (Ionic 
Metal-Phosphonates), are relatively scarce. However, notable examples are found in the literature, and are briefly presented below.

The hydrated salt $\left[\mathrm{Co}\left(\mathrm{NH}_{3}\right)_{6}\right]\left(\mathrm{O}_{3} \mathrm{P}\left(\mathrm{C}_{6} \mathrm{H}_{4}\right)_{2} \mathrm{COO}\right) \cdot 4 \mathrm{H}_{2} \mathrm{O}$ was crystallized from an aqueous ammonia solution of 4-phosphono-biphenyl-4'-carboxylic acid [11]. In a similar approach, 4-phosphonobenzoic acid was crystallized with hexaaquacobalt(II) [12]. The compound $\left[\mathrm{Cd}_{2} \mathrm{Cl}_{4}\left(\mathrm{H}_{2} \mathrm{O}\right)_{6}\right]_{0.5}\left[\mathrm{H}_{4} \mathrm{~L}\right]$ [L = 2-morpholinoethyliminobis(methylenephosphonic acid)] contains a $\mathrm{Cd}$ chlorodimer as the cationic moiety [13]. The salt $\left[\mathrm{Ni}(\text { phen })_{3}\right]\left(\mathrm{H}_{7} \mathrm{~L}_{2}\right)_{0.5}\left(\mathrm{H}_{5} \mathrm{~L}_{2}\right)_{0.5} \cdot 2 \mathrm{H}_{2} \mathrm{O}$ (phen $=1,10$-phenanthroline, $\mathrm{L}=$ hydroxyethylidene-1,1-diphosphonic acid) showed two forms of the ligand in the same structure, with different degrees of deprotonation [14]. A series of divalent transition metal phosphonates containing hydrogen-bonded layers of phenylphosphonate anions, namely $\left[\mathrm{M}(\text { phen })_{3}\right] \cdot \mathrm{C}_{6} \mathrm{H}_{5} \mathrm{PO}_{3} \cdot 11 \mathrm{H}_{2} \mathrm{O}\left[\mathrm{M}=\mathrm{Co}^{2+}, \mathrm{Ni}^{2+}, \mathrm{Cu}^{2+}\right]$ and $\left[\mathrm{Cd}(\text { phen })_{3}\right] \cdot \mathrm{C}_{6} \mathrm{H}_{5} \mathrm{PO}_{3} \mathrm{H} \cdot \mathrm{Cl} \cdot 7 \mathrm{H}_{2} \mathrm{O}$ were synthesized and structurally characterized by single-crystal $\mathrm{X}$-ray diffraction methods [15]. The synthesis and crystal structures of five new analogues of the supramolecular copper(II) arylphosphonate $\left[\mathrm{Cu}(\text { phen })_{2} \mathrm{Cl}\right]\left[\left(\mathrm{C}_{6} \mathrm{H}_{5} \mathrm{PO}_{3} \mathrm{H}_{2}\right)\left(\mathrm{HO}_{3} \mathrm{PC}_{6} \mathrm{H}_{5}\right)\right]$ were reported. The structures contain substituted phenylphosphonic acids, and are of the general formula $\left[\mathrm{Cu}(\text { phen })_{2} \mathrm{Cl}\right]\left[\left(\mathrm{XPO}_{3} \mathrm{H}_{2}\right)\left(\mathrm{HO}_{3} \mathrm{PX}\right)\right] \cdot \mathrm{Z}$, where $\mathrm{X}=0-\mathrm{CH}_{3}\left(\mathrm{C}_{6} \mathrm{H}_{4}\right)$; $\mathrm{X}=p-\mathrm{CH}_{3}\left(\mathrm{C}_{6} \mathrm{H}_{4}\right), \mathrm{Z}=\mathrm{H}_{2} \mathrm{O} \cdot 2 \mathrm{CH}_{3} \mathrm{CH}_{2} \mathrm{OH} ; \mathrm{X}=o-\mathrm{NO}_{2}\left(\mathrm{C}_{6} \mathrm{H}_{4}\right), m-\mathrm{NO}_{2}\left(\mathrm{C}_{6} \mathrm{H}_{4}\right) ; \mathrm{X}=m-\mathrm{NO}_{2}\left(\mathrm{C}_{6} \mathrm{H}_{4}\right) ;$ $\mathrm{X}=\mathrm{C}_{10} \mathrm{H}_{7}$ [16]. The salt $\left[\mathrm{Mg}_{1.5}\left(\mathrm{H}_{2} \mathrm{O}\right)_{9}\right] \cdot\left(\mathrm{L}-\mathrm{H}_{2}\right)_{1.5} \cdot 6 \mathrm{H}_{2} \mathrm{O}\left(\mathrm{L}-\mathrm{H}_{2}=\mathrm{O}_{3} \mathrm{PCH}_{2} \mathrm{~N}(\mathrm{H})\left(\mathrm{C}_{4} \mathrm{H}_{8}\right) \mathrm{N}(\mathrm{H}) \mathrm{CH}_{2} \mathrm{PO}_{3}\right.$, $\mathrm{N}, \mathrm{N}^{\prime}$-piperazine-bis(methylenephosphonic acid) was hydrothermally synthesized and structurally characterized [17]. The crystal structure of the zinc hexaaqua compound $\left[\mathrm{Zn}\left(\mathrm{H}_{2} \mathrm{O}\right)_{6}\right][$ TDTMP] (TDTMP $=$ tetramethylenediamine-tetrakis(methylenephosphonate)) was reported [18]. Alkaline-earth metal phosphates containing nitrogen-donor ligands were prepared by the reaction of alkaline-earth metal acetates $\mathrm{M}(\mathrm{OAc})_{2} \cdot \mathrm{xH}_{2} \mathrm{O}(\mathrm{M}=\mathrm{Mg}, \mathrm{Ca}, \mathrm{Sr}, \mathrm{Ba})$ with 2,6-diisopropylphenylphosphate $\left(\mathrm{dippH}_{2}\right)$. Interaction of strontium or barium acetate with dippH $\mathrm{H}_{2}$ in methanol at room temperature leads to the isolation of ionic phosphates $\left[\left\{\mathrm{M}_{2}\left(\mu-\mathrm{H}_{2} \mathrm{O}\right)_{4}\left(\mathrm{H}_{2} \mathrm{O}\right)_{10}\right\}\{\text { dipp }\}_{2}\right] \cdot 4 \mathrm{~L}\left[\mathrm{M}=\mathrm{Sr}, \mathrm{L}=\mathrm{CH}_{3} \mathrm{OH} ; \mathrm{M}=\mathrm{Ba}\right.$, $\mathrm{L}=\mathrm{H}_{2} \mathrm{O}$ ] [19]. The structure of the compound bis(hydrogen diphenylmethylphosphonato)-magnesium octahydrate contains polar and non-polar layers. The polar layers contain $\mathrm{Mg}\left(\mathrm{H}_{2} \mathrm{O}\right)_{6}{ }^{2+}$ ions, water of hydration and the phosphonate $\mathrm{O}$ atoms, and the non-polar layers contain benzhydryl groups. Two-dimensional hydrogen-bonding networks link $\mathrm{Mg}\left(\mathrm{H}_{2} \mathrm{O}\right)_{6}{ }^{2+}$ and the water of hydration to the phosphonate $\mathrm{O}$ atoms [20]. Three 1D nickel coordination polymers based on $\mathrm{P}, \mathrm{P}^{\prime}$-diphenylethylenediphosphinic acid and three different bis-pyridine co-ligands, namely 4,4'-bipyridine, 1,2-bis(4-pyridyl)ethane and 1,2-bis(4-pyridyl)ethane, were prepared in mild hydrothermal conditions. They all contained 1D "Ni-bipyridyl" chains, with the phosphinate playing the role of the counterion [21]. The synthesis and crystal structure of $\mathrm{Mg}(2-\mathrm{AEPH})_{2} \cdot 8 \mathrm{H}_{2} \mathrm{O}$ (2-AEPH $=2$-aminoethylphosphonate) were reported [22]. The compound is built from octahedral magnesium hexaaqua dications, uncoordinated 2- $\mathrm{AEPH}^{-}$anions, and interstitial water molecules. The latter have no metal contacts but are engaged in hydrogen bonding, in which the water molecules, the (protonated) amino functions and the $\mathrm{O}$-acceptor sites of the anions participate. The structures of the alkaline earth metal $(\mathrm{Mg}, \mathrm{Ca}, \mathrm{Sr}$ and $\mathrm{Ba}$ ) complexes with (4-aminophenyl)arsonic acid (p-arsanilic acid) have been determined [23]. Of these, only the $\mathrm{Mg}$ analog, hexaaquamagnesium bis[hydrogen (4-aminophenyl)arsonate] tetrahydrate, $\left[\mathrm{Mg}\left(\mathrm{H}_{2} \mathrm{O}\right)_{6}\right]\left(\mathrm{C}_{6} \mathrm{H}_{7} \mathrm{AsNO}_{3}\right) \cdot 4 \mathrm{H}_{2} \mathrm{O}$, is ionic. The octahedral $\left[\mathrm{Mg}\left(\mathrm{H}_{2} \mathrm{O}\right)_{6}\right]^{2+}$ cation, the two hydrogen p-arsanilate anions and the four water molecules of solvation form a three-dimensional network structure through inter-species $\mathrm{O}-\mathrm{H}$ and $\mathrm{N}-\mathrm{H}$ hydrogen-bonding interactions with water and arsonate $\mathrm{O}$-atom and amine $\mathrm{N}$-atom acceptors.

In this study we present the synthesis and structural characterization of five novel ionic metal phosphonates containing divalent metal ions, such as alkaline-earth metals $\left(\mathrm{M}=\mathrm{Mg}^{2+}, \mathrm{Ca}^{2+}\right.$, $\mathrm{Sr}^{2+}$ ) and the $3 \mathrm{D}$ transition metal $\mathrm{Ni}^{2+}$. The alkaline-earth metal compounds contain the aromatic amino-phosphonate ligand $p$-aminobenzylphosphonic acid $\left(\mathrm{H}_{2} \mathrm{PABPA}\right)$, or the tetraphosphonic acid ligand tetramethylenediamine-tetrakis (methylenephosphonic acid) $\left(\mathrm{H}_{8} \mathrm{TDTMP}\right.$ ) (when $\mathrm{M}=\mathrm{Mg}^{2+}$ ). The two $\mathrm{Ni}^{2+}$-containing compounds both contain the ligand 1,2-ethylenediphosphonic acid (EDPA), 
but one of them also contains the bridging co-ligand 4,4'-bipyridine. The latter is a $\mathrm{Ni}-4,4^{\prime}$-bipyridine coordination polymer having the EDPA as the counterion. Schematic structures of the ligand used herein are presented in Figure 1.

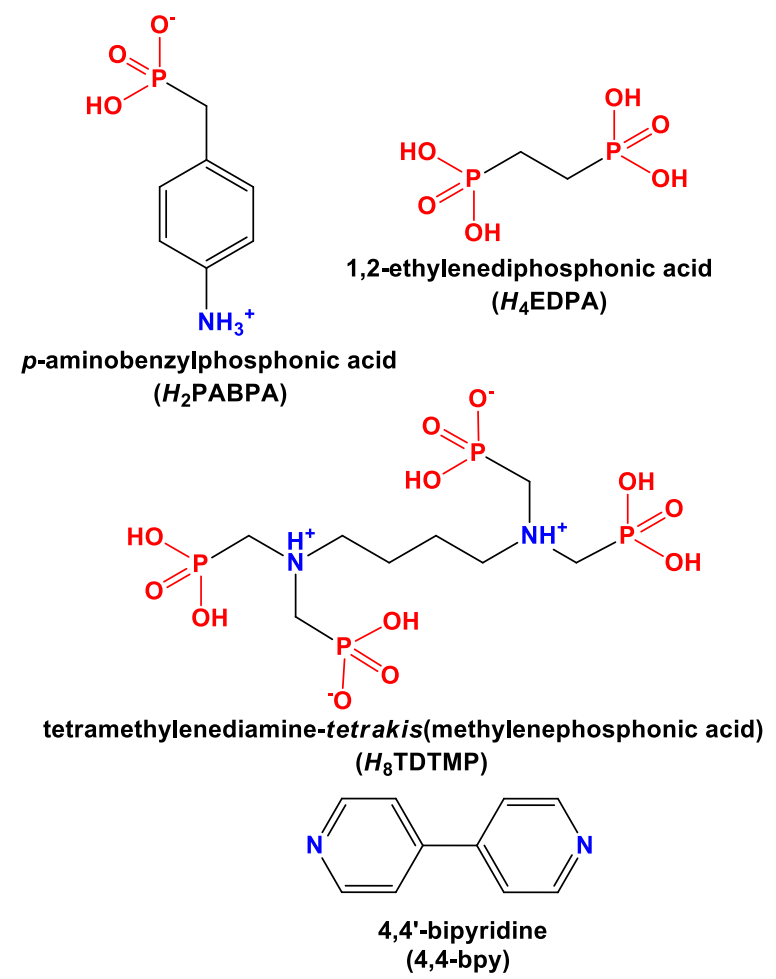

Figure 1. Phosphonic acids and N-heterocyclic ligand used in this paper. Phosphonato groups are highlighted in red, and $\mathrm{N}$ groups in blue. Amine-containing ligands are shown in their zwitterionic form.

\section{Materials and Methods}

\subsection{Instrumentation}

${ }^{1} \mathrm{H},{ }^{31} \mathrm{P}\left\{{ }^{1} \mathrm{H}\right\}$ NMR spectra were recorded on a Jeol JNM-ECZ 400S Research FT NMR spectrometer (JEOL Ltd., Tokyo, Japan) operating at $400 \mathrm{MHz}$ and $161.7 \mathrm{MHz}$ for ${ }^{1} \mathrm{H}$ and ${ }^{31} \mathrm{P}$ nuclei, respectively. ATR-IR spectra were collected on a Thermo-Electron NICOLET 6700 FTIR optical spectrometer (Thermo Fisher Scientific, Waltham, MA, USA). Elemental analyses (C, H, N) were measured on a Perkin-Elmer 2400 analyzer (Perkin-Elmer, Waltham, MA, USA). Thermogravimetric analysis (TGA) data were recorded on an SDT-Q600 analyzer from TA instruments (TA instruments, New Castle, DE, USA). The temperature varied from RT to $900^{\circ} \mathrm{C}$ at a heating rate of $10^{\circ} \mathrm{C} \cdot \mathrm{min}^{-1}$. Measurements were carried out on samples in open platinum crucibles under air flow.

\subsection{General}

Starting materials were of reagent grade purity, obtained from commercial sources, and used without further purification. Deionized (DI) water was purified by a cation-exchange column.

\subsection{Synthesis of 4-(bromomethyl)nitrobenzene}

A $100 \mathrm{~mL}$ flask was charged with 4-(hydroxymethyl)nitrobenzene (5.00 g, $0.0326 \mathrm{~mol})$, and 30\% $\mathrm{HBr}$ solution in glacial acetic acid $(35 \mathrm{~mL})$. The obtained mixture was stirred at gentle reflux for $2 \mathrm{~h}$. After cooling down, $48 \% \mathrm{HBr}$ solution in water $(20 \mathrm{~mL})$ was added in order to precipitate as much crude 4-(bromomethyl)nitrobenzene as possible. The obtained brownish solid was filtered out, dissolved in chloroform and passed through a thick plug of finely ground $\mathrm{K}_{2} \mathrm{CO}_{3}$, to remove acidic impurities 
and residual water. After solvent evaporation, crude 4-(bromomethyl)nitrobenzene was crystallized from hexanes affording light beige crystals. Yield: $6.41 \mathrm{~g}(91 \%)$. Spectral data match those previously reported [24]. ${ }^{1} \mathrm{H}$ NMR $\left(400 \mathrm{MHz}, \mathrm{CDCl}_{3}\right): \delta 8.20\left(\mathrm{~d},{ }^{3} J_{\mathrm{HH}}=8.4 \mathrm{~Hz}, 2 \mathrm{H}\right), 7.55\left(\mathrm{~d},{ }^{3} \mathrm{~J}_{\mathrm{HH}}=8.4 \mathrm{~Hz}, 2 \mathrm{H}\right)$, $4.51(\mathrm{~s}, 2 \mathrm{H})$.

\subsection{Synthesis of 4-(diethoxyphosphorylmethyl)nitrobenzene}

A three-neck $50 \mathrm{~mL}$ flask fitted with trap and gas inlet was charged with 4-(bromomethyl)nitrobenzene $(5.00 \mathrm{~g}, 0.0231 \mathrm{~mol})$, and triethyl phosphite $(10 \mathrm{~mL}, 0.0583 \mathrm{~mol})$. The mixture was heated to $120^{\circ} \mathrm{C}$ under constant flow of nitrogen. Ethyl bromide, which is a coproduct of the Arbuzov reaction, was collected in the trap. After two hours of reaction the volatiles were distilled off under reduced pressure at the same temperature. Dark orange-colored crude product was subjected to column chromatography (silica gel, eluent: ethyl acetate, $R_{\mathrm{f}}=0.40$ ) yielding yellowish oil. Yield: $5.63 \mathrm{~g}(89 \%)$. Spectral data matched those previously reported [25]. ${ }^{1} \mathrm{H}$ NMR $(400 \mathrm{MHz}$, $\left.\mathrm{CDCl}_{3}\right): \delta 8.24\left(\mathrm{~d},{ }^{3} \mathrm{~J}_{\mathrm{HH}}=8.7 \mathrm{~Hz}, 2 \mathrm{H}\right), 7.54\left(\mathrm{dd},{ }^{3} \mathrm{~J}_{\mathrm{HH}}=8.7 \mathrm{~Hz},{ }^{4} \mathrm{~J}_{\mathrm{PH}}=2.5 \mathrm{~Hz}, 2 \mathrm{H}\right), 3.93(\mathrm{~m}, 4 \mathrm{H}), 3.30(\mathrm{~d}$, $\left.{ }^{2} J_{P H}=22.4 \mathrm{~Hz}, 2 \mathrm{H}\right), 1.32\left(\mathrm{t},{ }^{3} J_{\mathrm{HH}}=7.0 \mathrm{~Hz}, 6 \mathrm{H}\right) .{ }^{31} \mathrm{P}\left\{{ }^{1} \mathrm{H}\right\} \mathrm{NMR}\left(161.7 \mathrm{MHz}, \mathrm{CDCl}_{3}\right): \delta 25.10(\mathrm{~s})$.

\subsection{Synthesis of 4-(diethoxyphosphorylmethyl)aniline}

This procedure is an adaptation of a reduction protocol employed for the synthesis of 4-(diethoxyphosphoryl)aniline [26]. A $250 \mathrm{~mL}$ flask was charged with 4-(diethoxyphosphorylmethyl)nitrobenzene $(4.80 \mathrm{~g}, 0.0175 \mathrm{~mol})$, triethylamine $(50 \mathrm{~mL}, 0.358 \mathrm{~mol})$, and $100 \mathrm{mg} 10 \% \mathrm{Pd} / \mathrm{C}$ catalyst. The reaction mixture was preheated to $50{ }^{\circ} \mathrm{C}$ and $90 \%$ Formic acid $(8 \mathrm{~mL}$, $0.18 \mathrm{~mol}$ ) was added in small portions. Note that the reaction is strongly exothermic, and that hydrogen gas is evolved. After addition of all formic acid the reflux was maintained for $30 \mathrm{~min}$, then the reaction mixture was cooled down, and evaporated. The crude product was dissolved in chloroform $(100 \mathrm{~mL})$, extracted with water $(2 \times 50 \mathrm{~mL})$, and brine $(50 \mathrm{~mL})$. The organic phase was collected, dried with $\mathrm{K}_{2} \mathrm{CO}_{3}$, and evaporated. Column chromatography (silica gel, eluent: ethyl acetate, $\mathrm{R}_{\mathrm{f}}=0.22$ ) provided pure 4-(diethoxyphosphorylmethyl)aniline as a light yellow oil that crystallizes upon standing. Yield: $3.35 \mathrm{~g}(79 \%)$. Spectral data match those previously reported [27]. ${ }^{1} \mathrm{H} \mathrm{NMR}\left(400 \mathrm{MHz}, \mathrm{CDCl}_{3}\right) \delta 7.05$ $\left(\mathrm{dd},{ }^{3} J_{H H}=8.6 \mathrm{~Hz},{ }^{4} J_{P H}=2.6 \mathrm{~Hz}, 2 \mathrm{H}\right), 6.61\left(\mathrm{~d},{ }^{3} J_{H H}=7.9 \mathrm{~Hz}, 2 \mathrm{H}\right), 4.05-3.88(\mathrm{~m}, 2 \mathrm{H}), 3.61(\mathrm{br} . \mathrm{s}, 2 \mathrm{H})$, $3.02\left(\mathrm{~d},{ }^{2} J_{P H}=20.9 \mathrm{~Hz}, 4 \mathrm{H}\right), 1.22\left(\mathrm{td},{ }^{3} J_{\mathrm{HH}}=7.1,{ }^{4} J_{P H}=0.5 \mathrm{~Hz}, 6 \mathrm{H}\right) .{ }^{31} \mathrm{P}\left\{{ }^{1} \mathrm{H}\right\} \mathrm{NMR}\left(161.7 \mathrm{MHz}, \mathrm{CDCl}_{3}\right)$ : $\delta 27.83(\mathrm{~s})$.

\subsection{Synthesis of 4-(dihydroxyphosphorylmethyl)aniline ( $\left.\mathrm{H}_{2} P A B P A\right)$}

4-(Diethoxyphosphorylmethyl)aniline $(3.20 \mathrm{~g}, 0.0131 \mathrm{~mol})$, concentrated hydrochloric acid $(25 \mathrm{~mL})$ and water $(25 \mathrm{~mL})$ were mixed together in a $100 \mathrm{~mL}$ flask. The obtained mixture was heated at reflux for $20 \mathrm{~h}$. After hydrolysis the reaction mixture was evaporated to dryness. Crude product was boiled with ethanol $(30 \mathrm{~mL})$ for $30 \mathrm{~min}$, cooled down and left overnight. A beige precipitate was filtered out and dried, providing pure 4-(dihydroxyphosphorylmethyl)aniline. Yield: $2.19 \mathrm{~g}(89 \%) .{ }^{1} \mathrm{H} \mathrm{NMR}(400 \mathrm{MHz}$, $\left.\mathrm{D}_{2} \mathrm{O}+\mathrm{D}_{2} \mathrm{SO}_{4}\right) \delta 7.16\left(\mathrm{dd},{ }^{3} J_{\mathrm{HH}}=8.8 \mathrm{~Hz},{ }^{4} J_{P H}=2.6 \mathrm{~Hz}, 2 \mathrm{H}\right), 7.09\left(\mathrm{dd},{ }^{3} J_{\mathrm{HH}}=8.8 \mathrm{~Hz},{ }^{5} J_{P H}=0.8 \mathrm{~Hz}, 2 \mathrm{H}\right)$, $2.99\left(\mathrm{~d},{ }^{2} J_{P H}=21.5 \mathrm{~Hz}, 2 \mathrm{H}\right) .{ }^{31} \mathrm{P}\left\{{ }^{1} \mathrm{H}\right\} \mathrm{NMR}\left(161.7 \mathrm{MHz}, \mathrm{D}_{2} \mathrm{O}+\mathrm{D}_{2} \mathrm{SO}_{4}\right): \delta 25.48(\mathrm{~s})$.

\subsection{Synthesis of $\left[\mathrm{Mg}\left(\mathrm{H}_{2} \mathrm{O}\right)_{6}\right] \cdot[\mathrm{HPABPA}]_{2} \cdot 6 \mathrm{H}_{2} \mathrm{O}(\mathrm{Mg}-\mathrm{PABPA})$}

Solid $\mathrm{H}_{2}$ PABPA ( $132 \mathrm{mg}, 0.7 \mathrm{mmol}$ ) was added to $140 \mathrm{~mL}$ of deionized water in a $250 \mathrm{~mL}$ glass beaker. A small quantity of $2 \mathrm{M} \mathrm{NaOH}$ solution was added until the $\mathrm{pH}$ of the solution reached the value of $\sim 12.0$. The solution was then heated to $80^{\circ} \mathrm{C}$ and stirred vigorously until all the solid $\mathrm{H}_{2}$ PABPA dissolved. The solution was left to reach room temperature and then a small amount of a $2 \mathrm{M} \mathrm{HCl}$ solution was added until the $\mathrm{pH}$ dropped to 7.7. In a separate glass beaker, a quantity of $\mathrm{MgCl}_{2} \cdot 6 \mathrm{H}_{2} \mathrm{O}$ (70 mg, $\left.0.35 \mathrm{mmol}\right)$ was dissolved in $70 \mathrm{~mL}$ of DI water. The two solutions were finally transferred to a polypropylene vessel and mixed under vigorous stirring. The $\mathrm{pH}$ of the resulting solution was adjusted to 7.0. This clear, colorless solution was left to stand at room temperature for 
$\sim 2$ weeks and product crystallization was achieved via slow evaporation of the solvent. The dark brown crystals were isolated by filtration, washed with small amounts of DI water, and left to air-dry. Yield: $55 \mathrm{mg}(35 \%)$. Elemental analysis for $\left[\mathrm{Mg}\left(\mathrm{H}_{2} \mathrm{O}\right)_{6}\right] \cdot[\mathrm{HPABPA}]_{2} \cdot 6 \mathrm{H}_{2} \mathrm{O}, \mathrm{MW} 612.74$. Calculated (Found) \%: C 27.42 (27.39), H 6.85 (6.04), N 4.57 (4.60).

\subsection{Synthesis of $\left[\mathrm{Ca}\left(\mathrm{H}_{2} \mathrm{O}\right)_{8}\right] \cdot[\mathrm{HPABPA}]_{2}(\mathrm{Ca}-\mathrm{PABPA})$}

The same method as for $\left[\mathrm{Mg}\left(\mathrm{H}_{2} \mathrm{O}\right)_{6}\right] \cdot[\mathrm{HPABPA}]_{2} \cdot 6 \mathrm{H}_{2} \mathrm{O}$ was used for this synthesis. The reactants used were: $\mathrm{H}_{2}$ PABPA ( $132 \mathrm{mg}, 0.7 \mathrm{mmol}$ ) and $\mathrm{CaCl}_{2} \cdot 2 \mathrm{H}_{2} \mathrm{O}(50 \mathrm{mg}, 0.35 \mathrm{mmol})$. Yield: $66 \mathrm{mg}(34 \%)$. Elemental analysis for $\left[\mathrm{Ca}\left(\mathrm{H}_{2} \mathrm{O}\right)_{8}\right] \cdot[\mathrm{HPABPA}]_{2}, \mathrm{MW}$ 556.45. Calculated (Found)\%: C 29.39 (30.19), H 5.97 (6.11), N 4.92 (5.03).

\subsection{Synthesis of $\left[\mathrm{Sr}\left(\mathrm{H}_{2} \mathrm{O}\right)_{8}\right] \cdot[\mathrm{HPABPA}]_{2}(\mathrm{Sr}-\mathrm{PABPA})$}

The same method as for $\left[\mathrm{Mg}\left(\mathrm{H}_{2} \mathrm{O}\right)_{6}\right] \cdot[\mathrm{HPABPA}]_{2} \cdot 6 \mathrm{H}_{2} \mathrm{O}$ was used for this synthesis. The reactants used were: $\mathrm{H}_{2}$ PABPA (132 mg, $\left.0.7 \mathrm{mmol}\right)$ and $\mathrm{SrCl}_{2} \cdot 6 \mathrm{H}_{2} \mathrm{O}(90 \mathrm{mg}, 0.35 \mathrm{mmol})$. Yield: $70 \mathrm{mg}(33 \%)$. Elemental analysis for $\left[\mathrm{Sr}\left(\mathrm{H}_{2} \mathrm{O}\right)_{8}\right] \cdot[\mathrm{HPABPA}]_{2}, \mathrm{MW}$ 603.99. Calculated (Found)\%: C 27.82 (25.87), H 5.63 (5.13), N 4.64 (4.35).

\subsection{Synthesis of $\left[\mathrm{Ni}\left(\mathrm{H}_{2} \mathrm{O}\right)_{6}\right] \cdot\left[\mathrm{H}_{2} \mathrm{EDPA}\right] \cdot \mathrm{H}_{2} \mathrm{O}(\mathrm{Ni}-\mathrm{EDPA})$}

$\mathrm{Ni}\left(\mathrm{NO}_{3}\right)_{2} \cdot 6 \mathrm{H}_{2} \mathrm{O}(290 \mathrm{mg}, 1.0 \mathrm{mmol})$ and $\mathrm{H}_{4} \mathrm{EDPA}(196 \mathrm{mg}, 1.0 \mathrm{mmol})$ were simultaneously dissolved in $\mathrm{DI}$ water $(100 \mathrm{~mL})$ in a polypropylene vessel under vigorous stirring and the $\mathrm{pH}$ of the solution was adjusted to 4.0 with a small quantity of a $2 \mathrm{M} \mathrm{NaOH}$ solution. This clear, greenish solution was left to stand at room temperature and product crystallization was achieved via slow evaporation of the solvent. Emerald green crystals formed after 15 days and were filtered and washed with a small quantity of DI water. Yield: $217 \mathrm{mg}(78 \%)$. Elemental analysis for $\left[\mathrm{Ni}\left(\mathrm{H}_{2} \mathrm{O}\right)_{6}\right] \cdot\left[\mathrm{H}_{2} \mathrm{EDPA}\right] \cdot \mathrm{H}_{2} \mathrm{O}$, MW 390.84. Calculated (Found)\%: C 6.14 (5.77), H 5.63 (5.53), N 0 (0.05).

\subsection{Synthesis of $\left\{\left[\mathrm{Ni}\left(4,4^{\prime}-\right.\right.\right.$ bpy $\left.)\left(\mathrm{H}_{2} \mathrm{O}\right)_{4}\right] \cdot\left[\mathrm{H}_{2} \mathrm{EDPA}\right] \cdot \mathrm{H}_{2} \mathrm{O}_{n}$ (Ni-bpy-EDPA)}

$\mathrm{Ni}\left(\mathrm{NO}_{3}\right)_{2} \cdot 6 \mathrm{H}_{2} \mathrm{O}(290 \mathrm{mg}, 1.0 \mathrm{mmol}), \mathrm{H}_{4} \mathrm{EDPA}(196 \mathrm{mg}, 1.0 \mathrm{mmol})$, and 4,4'-bpy (156 mg, $\left.1.0 \mathrm{mmol}\right)$ were simultaneously dissolved in DI water $(100 \mathrm{~mL})$ in a polypropylene $(\mathrm{PP})$ vessel under vigorous stirring and the $\mathrm{pH}$ of the solution was adjusted to 5.0 with a small quantity of a $2 \mathrm{M} \mathrm{NaOH}$ solution. This clear, greenish solution was left to stand at room temperature and product crystallization was achieved via slow evaporation of the solvent. Emerald green crystals formed after 15 days and were filtered and washed with a small quantity of DI water. Yield: $219 \mathrm{mg}(45 \%)$. Elemental analysis for $\left[\mathrm{Ni}\left(4,4^{\prime}\right.\right.$-bpy) $\left.\left(\mathrm{H}_{2} \mathrm{O}\right)_{4}\right] \cdot\left[\mathrm{H}_{2} \mathrm{EDPA}\right] \cdot \mathrm{H}_{2} \mathrm{O}$, MW 511.00. Calculated (Found)\%: C 28.18 (28.42), $\mathrm{H} 5.09$ (5.73), $\mathrm{N} 5.48$ (6.13).

\subsection{Synthesis of $\left[\mathrm{Mg}\left(\mathrm{H}_{2} \mathrm{O}\right)_{6}\right] \cdot\left[\mathrm{H}_{6} \mathrm{TDTMP}\right](\mathrm{Mg}$-TDTMP)}

In a PP vessel solid $\mathrm{H}_{8}$ TDTMP acid (46 mg, $0.1 \mathrm{mmol}$ ) was mixed with $\mathrm{MgCl}_{2} \cdot 6 \mathrm{H}_{2} \mathrm{O}(20 \mathrm{mg}$, $0.1 \mathrm{mmol}$ ) in $10 \mathrm{~mL}$ DI water under continuous stirring until complete dissolution of the solids. The $\mathrm{pH}$ was adjusted to $\sim 3.0$. The clear colorless solution was then left to stand at ambient conditions for partial solvent evaporation. A crystalline precipitate was obtained after 15 days, isolated by filtration, washed with DI water and left to dry under air. Yield $36 \mathrm{mg}(60 \%)$. Elemental analysis for $\left[\mathrm{Mg}\left(\mathrm{H}_{2} \mathrm{O}\right)_{6}\right] \cdot\left[\mathrm{H}_{6}\right.$ TDTMP], MW 594.56. Calculated (Found)\%: C 16.15 (16.31), H 5.72 (5.66), N 4.71 4.54).

\subsection{Crystal Data Collection And Refinement}

Crystals for measurements were handled under inert conditions. They were immersed in perfluoropolyether as a protecting oil for manipulation. Suitable single crystals were mounted on MiTeGen Micromounts ${ }^{\mathrm{TM}}$ and subsequently used for data collection. X-ray diffraction data for Ni-bpy-EDPA and Mg-TDTMP were collected at room temperature from a single-crystal mounted 
atop a glass fiber with cyanoacrylate glue, using a Bruker SMART APEX II diffractometer with graphite-monochromated Mo-K $\alpha$ radiation. Data for Mg-PABPA, Ca-PABPA, Sr-PABPA and Ni-EDPA were collected with a Bruker D8 Venture diffractometer. The data were processed with the APEX3 suite [28]. The structures were solved by direct methods [29], which revealed the position of all non-hydrogen atoms. These atoms were refined on $\mathrm{F}^{2}$ by a full-matrix least squares procedure using anisotropic displacement parameters [30]. All hydrogen atoms were located in difference Fourier maps and included as fixed contributions riding on attached atoms with isotropic thermal displacement parameters 1.2 or 1.5 times those of the respective atom. Crystallographic data for the reported structures have been deposited with the Cambridge Crystallographic Data Center as supplementary publication no. CCDC 1914866 - 1914868 and 1914870-1914872. Additional crystal data are shown in Table 1. Copies of the data can be obtained free of charge at http://www.ccdc.cam.ac.uk/products/csd/request.

Table 1. Selected crystallographic data for all compounds.

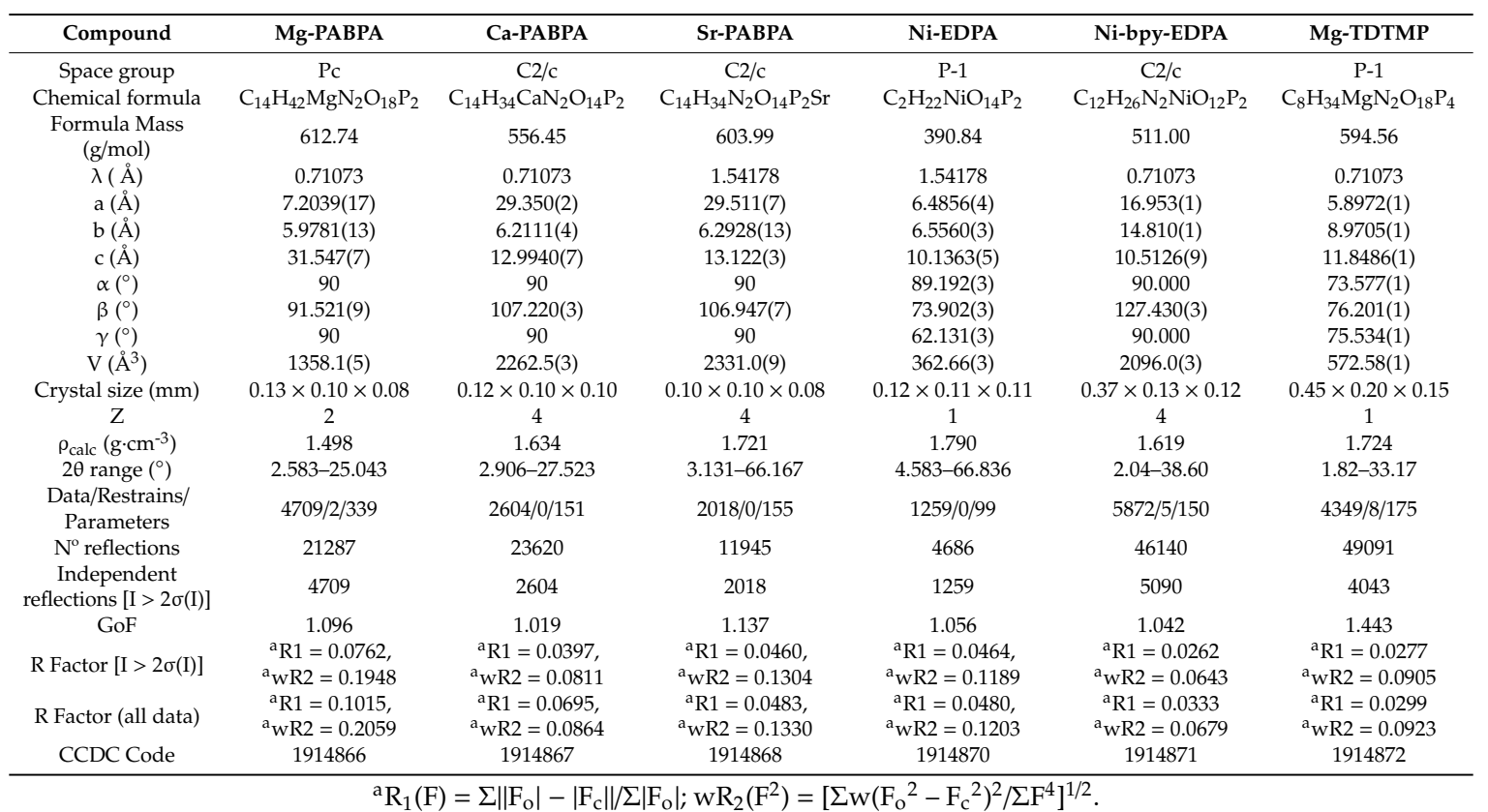

The structures of Ni-bpy-EDPA and Mg-TDTMP were solved by employing SHELXTL direct methods and refined by full-matrix least squares on $\mathrm{F}^{2}$, using the APEX2 software package [31]. All non-H atoms were refined with independent anisotropic displacement parameters. Hydrogen atoms were placed at calculated positions and refined using a riding model, except for the water and phosphonic acid $\mathrm{O}-\mathrm{H}$ hydrogens, which were located from the Fourier difference density maps and refined using a riding model with $\mathrm{O}-\mathrm{H}$ distance restraints. Crystallographic details are summarized in Table 1.

\subsection{Computational Studies}

Electronic Structure Calculations. DFT calculations [32] were performed at the B3LYP/6-31+G* [33-35] level to obtain the distribution of the electronic density $\rho$ of the ligands colored with the Molecular Electrostatic Potential value. Partial charges for all phosphonic oxygen atoms were calculated using the Mulliken [36] and Lowdin [37] Population Analysis. Comparison between the ligands that are used in this study and the non-electron withdrawing group (EWG) analogues should show the deficiency of electron density around the phosphonate groups as a result of the co-existence of the EWGs on each molecule. Furthermore, to better mimic the experimental conditions, the Polarization Continuum Model (PCM) [38] implied in GAMESS(US) [39,40] was used for all the calculations by adding solvent effects. The electronic densities were rendered using wxMacMolPlt [41]. The non EWGs analogs 
used were ethylphosphonic acid $\left(\mathbf{H}_{2} \mathbf{E P A}\right)$ for $\mathbf{H}_{4}$ EDPA and benzylphosphonic acid $\left(\mathbf{H}_{2} \mathbf{B P A}\right)$ for the $\mathrm{H}_{2}$ PABPA.

Computational Methodology. The starting geometries for all compounds except HPABPA $^{1-}$ were created using the molecular editor Avogadro [42] (Version 1.2.0) and the Universal Force field (UFF) [43]. The next step is the geometry refinement and it was done on the B3LYP/6-31 + G*/PCM level using GAMESS(US) [44-46]. The resulting energetically minimized structures were used for the electronic structure calculations. Since the ligand HPABPA $^{1-}$ is found as a dimer in all crystal structures, we used both the monomer and the dimer of HPABPA ${ }^{1-}$ for all calculations. Therefore, for the starting geometry of the dimer anion of the ligand, the (HPABPA $\left.{ }^{1-}\right)_{2}$ supramolecule was isolated from the CIF file of the Sr-PABPA compound using the Avogadro software. This geometry was refined at the B3LYP/6-31 $+\mathrm{G}^{*} / \mathrm{PCM}$ level using GAMESS(US). The resulting, energetically minimized structure was used for the electronic structure calculations. The geometry of the monomer of $\mathbf{H P A B P A}^{1-}$ was created using Avogadro and the MMFF94 Molecular Force Field created by Merck [47]. The Geometry refinement and the electronic calculations were done at the same level of theory as for the rest compounds.

\section{Results}

\subsection{Synthetic Considerations}

One of the major factors affecting metal phosphonate syntheses is $\mathrm{pH}$ [48]. In most cases, low $\mathrm{pH}$ favors protonation of the phosphonate groups and drastically reduced affinity for metal ions. In contrast, high $\mathrm{pH}$ values cause deprotonation, high negative charge on the phosphonate and rapid formation and precipitation of an amorphous metal phosphonate product. Hence, for each metal/phosphonate system there is an optimum $\mathrm{pH}$ regime for crystalline product formation [49].

However, even if solution $\mathrm{pH}$ ensures electroneutrality, i.e., positive charge from the metal cation equals the negative charge from the phosphonate ligand, the ligand can be found to be non-coordinated (albeit deprotonated), acting simply as the counterion. The metal ion is commonly found bound by water molecules in an aqua complex or coordinated by other ligands present in the system. Other electron-withdrawing, or cationic moieties on the phosphonate ligand backbone may withdraw electron density from the anionic phosphonate group, thus making it less nucleophilic.

The PABPA was found as the "free" anion in the structures of Mg-PABPA, Ca-PABPA, and Sr-PABPA. The phosphonate moiety was found to be doubly-deprotonated, whereas the amine group was protonated. This renders the entire ligand monoanionic, hence each divalent metal center requires two HPABPA ligands for charge balance. All metal centers were coordinated by water molecules (six in the case of $\mathrm{Mg}$, and eight in the case of $\mathrm{Ca}$ and $\mathrm{Sr}$ ). In spite of the fact that the phosphonate moiety was doubly deprotonated, it remained non-coordinated, apparently due to the decrease in its negative charge because of the $-\mathrm{NH}_{3}{ }^{+}$group (this aspect is analyzed in the DFT calculations section, vide infra). In this case, water as a ligand was stronger than the phosphonate oxygens.

A similar situation was seen for the $\mathbf{H}_{6}$ TDTMP $^{2-}$ tetraphosphonate ligand in Mg-TDTMP. Here, every phosphonate moiety was singly-deprotonated, whereas the $\mathrm{N}$ atom (a tertiary amine) was found to be protonated. This is the common bis-anionic form of this ligand at the $\mathrm{pH}$ region 2-4 [50]. Again, it is assumed that the $\mathrm{NH}^{+}$moieties deplete the phosphonate moieties of anionic charge, thus making them less nucleophilic.

In the $\mathbf{H}_{2}$ EDPA $^{2-}$ ligand, and in the salt Ni-EDPA, each phosphonate moiety was singly-deprotonated, thus rendering the ligand a " $2-$ " anion, balancing the " $2+$ " charge of the $\left[\mathrm{Ni}\left(\mathrm{H}_{2} \mathrm{O}\right)_{6}\right]^{2+}$ cation. In spite of the absence of any electron-withdrawing moieties in $\mathbf{H}_{2} \mathbf{E D P A}^{2-}$ it still remained non-coordinated in the Ni-EDPA salt. This has been observed before in the salt [Ni(2,2'-bpy)( $\left.\left.\mathbf{H}_{2} \mathrm{O}\right)_{4}\right] \cdot\left[\mathrm{H}_{2}\right.$ EDPA] [51]. Similarly, in the cationic coordination polymer Ni-bpy-EDPA the $\mathrm{Ni}^{2+}$ center was coordinated by four water molecules at equatorial positions, whereas the axial positions were occupied by the $\mathrm{N}$ atom of the bridging $4,4^{\prime}$-bpy ligand, leaving the $\mathbf{H}_{2}$ EDPA $^{2-}$ 
diphosphonate to play the role of the counterion for the cationic 1D chain. Here, the 4,4'-bpy ligand displayed strong affinity for the $\mathrm{Ni}^{2+}$ center, certainly stronger than the phosphonate oxygens.

\subsection{Materials Characterization}

Purity of all products was confirmed by elemental analyses (CHN) and powder X-ray diffraction (see Figures S1-S5, in the Supplementary Materials). In some cases (e.g., Mg-PABPA and Ni-EDPA) additional peaks were identified in the XRD diagrams, indicating the presence of impurities, but all our synthetic efforts did not improve product purity.

ATR-IR spectra for all ligands and metal-containing compounds are given in Figure S6, in the Supplementary Materials). For phosphonate-containing materials the region $900-1100 \mathrm{~cm}^{-1}$ is commonly used as a "fingerprint" region, in order to confirm changes in the environment of the phosphonate group. Phosphonate bands appeared in this region due to a combination of bands originating from $\mathrm{P}=\mathrm{O}, \mathrm{P}-\mathrm{OH}$ and $\mathrm{O}-\mathrm{P}-\mathrm{O}$ vibrations, similar to other reported compounds [52].

For example, for the "free" ligand $\mathrm{H}_{2}$ PABPA bands assigned to the $-\mathrm{PO}_{3}$ moiety appeared at 933,1064 , and $1085 \mathrm{~cm}^{-1}$. In the Mg-PABPA compound bands appeared in the same region, but at different positions, namely at 968, 1004, 1058, and $1091 \mathrm{~cm}^{-1}$. The spectra of Ca-PABPA and Sr-PABPA compounds (essentially identical, since these compounds are isostructural) showed the bands assigned to the $-\mathrm{PO}_{3}$ moiety in the same region, as expected, but slightly shifted, at 953,1028 , 1061, and $1097 \mathrm{~cm}^{-1}$. In the spectra of the "free" ligand $\mathbf{H}_{2}$ PABPA and Metal-PABPA compound, the bands due to the aromatic ring were essentially identical. Similar observations can be made for the "Nickel-EDPA" system. The "free" ligand $\mathbf{H}_{4}$ EDPA showed bands for the $-\mathrm{PO}_{3}$ moiety at $921,953,993$, and $1014 \mathrm{~cm}^{-1}$. Spectra for the Ni-EDPA compound showed these bands slightly shifted, at 926, 996, 1029 , and $1052 \mathrm{~cm}^{-1}$. Similarly, the Ni-bpy-EDPA compound showed very similar bands to those for Ni-EDPA, in addition to the strong peaks assigned to the 4,4'-bpy ligand.

Thermogravimetric analyses (TGA) revealed the thermal behavior of the compounds. For example, Mg-PABPA (Figure S7 in Supplementary Materials) demonstrated a number of consecutive losses. The first one $(\sim 16.5 \%)$, starts almost at RT and is completed at $\sim 100{ }^{\circ} \mathrm{C}$. It corresponds to removal of the lattice waters (six calculated, 5.6 found). The second loss ( 16.0), starting thereafter was complete at $\sim 150{ }^{\circ} \mathrm{C}$ and corresponded to removal of the Mg-coordinated waters (six calculated, 5.5 found). There were some additional small losses at temperatures above $200^{\circ} \mathrm{C}$, which might correspond to the loss of ammonia from the ligand. Similar observations can be noted for Ca-PABPA (Figure S8 in Supplementary Materials). The difference here is that Ca-PABPA had no lattice water molecules. Hence, the first substantial loss $(\sim 23 \%)$ completed at $\sim 100{ }^{\circ} \mathrm{C}$ corresponded to loss of the Ca-bound waters, followed by some small additional losses that were tentatively assigned to loss of ammonia from the ligand. Sr-PABPA (Figure S9 in Supplementary Materials) behaves similarly. Compound Ni-EDPA (Figure S10 in Supplementary Materials) loses all its water molecules (six that are Ni-coordinated and one in the lattice) in one single step $(\sim 37 \%)$ at $\sim 200^{\circ} \mathrm{C}$. Similarly, Ni-bpy-EDPA (Figure S11 in Supplementary Materials) showed a one-step loss ( $30.3 \%)$ of all of its water molecules (four that are $\mathrm{Ni}$-coordinated and one in the lattice). Loss of water molecules will create coordination sites for the phosphonate to bind, provided there is no ligand decomposition. As these phenomena are rather complex, they will be studied in detail and reported in a future publication.

\subsection{Crystallographic Description}

The structure of Mg-PABPA can be described as a salt with $\left[\mathrm{Mg}\left(\mathrm{H}_{2} \mathrm{O}\right)_{6}\right]^{2+}$ being the cation and two monoanionic HPABPA ${ }^{-}$ligands being the anions, see Figure 2a. Two HPABPA ${ }^{-}$ligands are required for charge balance. There are numerous hydrogen bonds between $\mathrm{Mg}$-bound water molecules, lattice water molecules, the phosphonate moiety and the protonated amine group. The structure (Figure $2 \mathrm{~b}, \mathrm{c}$ ) is composed of layers of $\left[\mathrm{Mg}\left(\mathrm{H}_{2} \mathrm{O}\right)_{6}\right]^{2+}$ cations and layers of $\mathrm{HPABPA}^{-}$ligands that run along the $\mathrm{b}$ axis. The orientation of the ligand was syn-anti, with the phosphonate groups sitting close to the $-\mathrm{NH}_{3}{ }^{+}$moieties. Lattice water molecules are situated in the vicinity of the $\mathrm{Mg}-\mathrm{OH}_{2},-\mathrm{PO}_{3}{ }^{2-}$ and 
$-\mathrm{NH}_{3}{ }^{+}$moieties forming a multitude of hydrogen bonds. The $\mathrm{Mg}^{2+}$ center $1 \mathrm{~s}$ situated in a near perfect octahedral environment, coordinated by six water molecules.
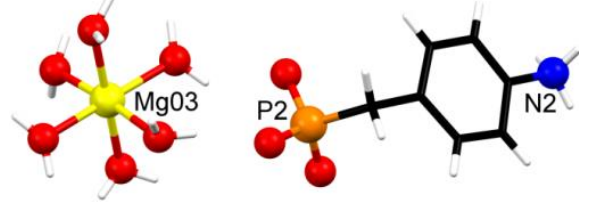

(a)

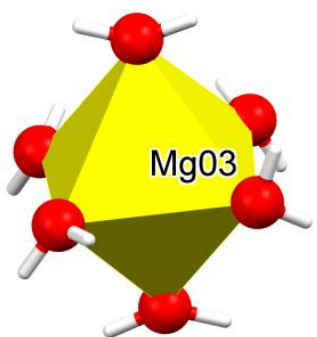

(b)

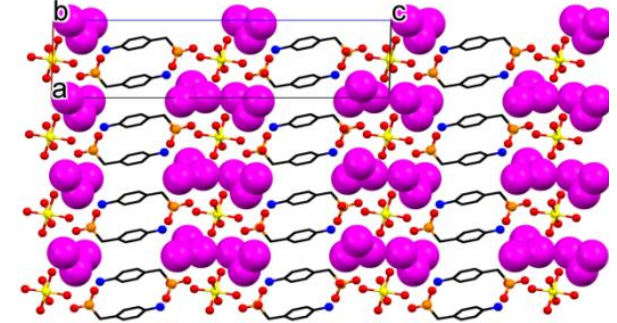

(c)

Figure 2. Crystal structure of Mg-PABPA: (a) View of the cation-anion pair; (b) The $\left[\mathrm{Mg}\left(\mathrm{H}_{2} \mathrm{O}\right)_{6}\right]^{2+}$ polyhedron; (c) Packing along the $\mathrm{b}$ axis. Lattice waters are shown as magenta spheres.

The salts Ca-PABPA and Sr-PABPA are isostructural, so only the former is discussed. The structure of Ca-PABPA can be described as a salt of $\left[\mathrm{Ca}\left(\mathrm{H}_{2} \mathrm{O}\right)_{8}\right]^{2+}$ aqua complex cation and two monoanionic HPABPA $^{-}$anions, see Figure $3 \mathrm{a}$. The $\mathrm{Ca}^{2+}$ center is coordinated by eight water molecules and is found in a coordination environment best described as bicapped prism, see Figure $3 \mathrm{~b}$. In contrast to the Mg-PABPA structure, there are no lattice water molecules in the lattice. The structure (Figure 3c) can be described as being composed of layers of $\left[\mathrm{Ca}\left(\mathrm{H}_{2} \mathrm{O}\right)_{8}\right]^{2+}$ cations and layers of $\mathbf{H P A B P A}^{-}$ligands that run along the $\mathrm{c}$ axis. The orientation of the ligand is syn-anti, with the phosphonate groups sitting close to the $-\mathrm{NH}_{3}{ }^{+}$moieties. The $-\mathrm{PO}_{3}{ }^{2-}$ and $-\mathrm{NH}_{3}{ }^{+}$moieties of the HPABPA ${ }^{-}$ligand form a multitude of hydrogen bonds with the Ca-coordinated water molecules.

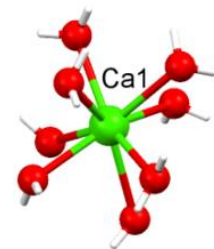

(a)

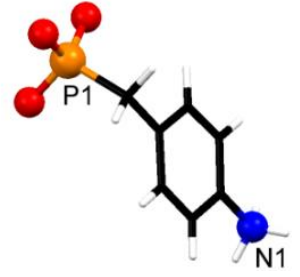

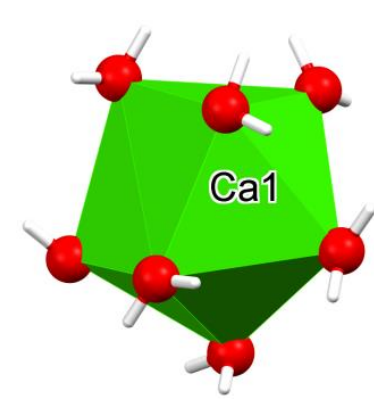

(b)

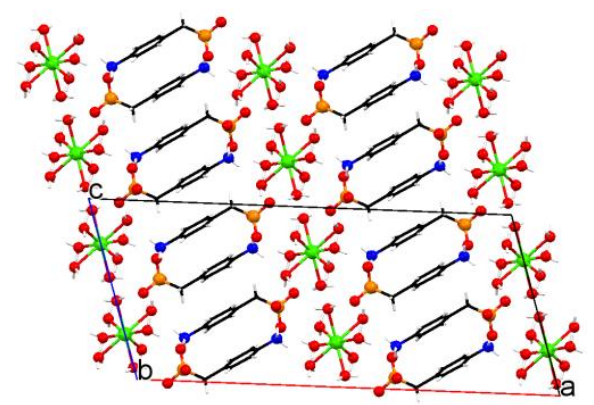

(c)

Figure 3. Crystal structure of Ca-PABPA: (a) View of the cation-anion pair; (b) The $\left[\mathrm{Ca}\left(\mathrm{H}_{2} \mathrm{O}\right)_{8}\right]^{2+}$ polyhedron; (c) Packing along the $b$ axis.

The structure of Mg-TDTMP can be described as a salt with $\left[\mathrm{Mg}\left(\mathrm{H}_{2} \mathrm{O}\right)_{6}\right]^{2+}$ being the cation and the bis-dianionic $\mathrm{H}_{6}$ TDTMP $^{2-}$ tetraphosphonate ligand being the anion, see Figure 4 a. One $\mathbf{H}_{6}$ TDTMP $^{2-}$ ligand is required for charge balance. There are numerous hydrogen bonds between $\mathrm{Mg}$-bound water molecules, the phosphonate moiety, and the tertiary protonated $\mathrm{NH}^{+}$group. The structure (Figure $4 \mathrm{c}$ ) is composed of layers of $\left[\mathrm{Mg}\left(\mathrm{H}_{2} \mathrm{O}\right)_{6}\right]^{2+}$ cations and layers of $\mathbf{H}_{6}$ TDTMP $^{2-}$ ligand that run along the $b$ axis. The orientation of the tetramethylene chain on the ligand is almost parallel to the $\mathrm{c}$ axis. There are no lattice water molecules in the structure. The $\mathrm{Mg}^{2+}$ center is situated in a near perfect octahedral environment, coordinated by six water molecules (Figure 4b). The salts Mg-TDTMP and Zn-TDTMP are isostructural [18]. 


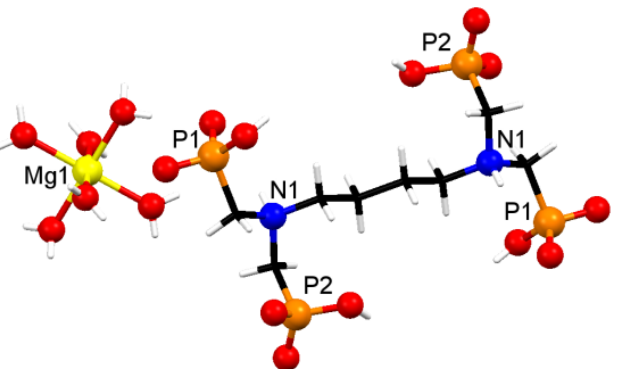

(a)

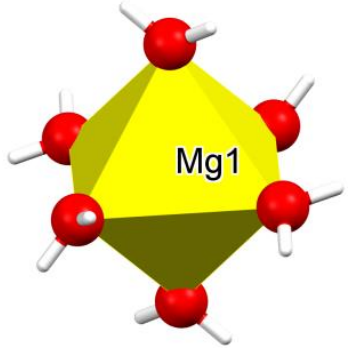

(b)

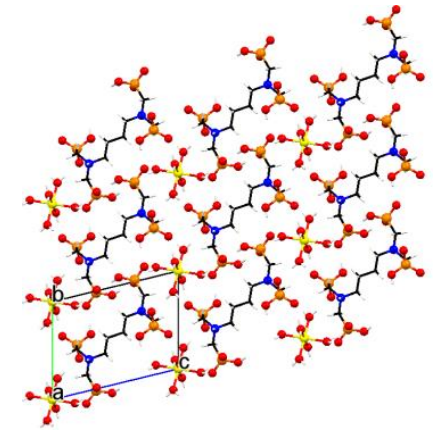

(c)

Figure 4. Crystal structure of Mg-DTTMP: (a) View of the cation-anion pair; (b) The $\left[\mathrm{Mg}\left(\mathrm{H}_{2} \mathrm{O}\right)_{6}\right]^{2+}$ polyhedron; (c) Packing along the a axis.

The crystal structure of Ni-EDPA is composed of the $\left[\mathrm{Ni}\left(\mathrm{H}_{2} \mathrm{O}\right)_{6}\right]^{2+}$ dication, the $\mathbf{H}_{2}$ EDPA $^{2-}$ dianion, and one lattice water molecule, see Figure $5 \mathrm{a}$. The $\mathrm{Ni}^{2+}$ center adopts an octahedral geometry, coordinated by six water molecules, see Figure $5 b$. One $\mathbf{H}_{2} \mathbf{E D P A}^{2-}$ ligand is required for charge balance. There are numerous hydrogen bonds between the Ni-bound water molecules, the lattice water molecule, and the phosphonate moieties. The structure (Figure $5 \mathrm{c}$ ) can be described as being composed of layers of $\left[\mathrm{Ni}\left(\mathrm{H}_{2} \mathrm{O}\right)_{6}\right]^{2+}$ cations and layers of the $\mathbf{H}_{2}$ EDPA $^{2-}$ ligand that run along the $b$ axis. The lattice water molecule is situated in the vicinity of the $\mathrm{Ni}-\mathrm{OH}_{2}$, and $-\mathrm{PO}_{3} \mathrm{H}^{-}$moieties, forming a multitude of hydrogen bonds.

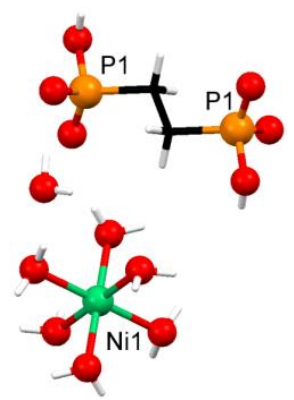

(a)

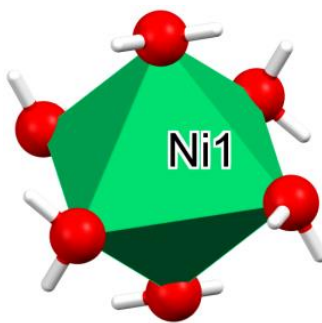

(b)

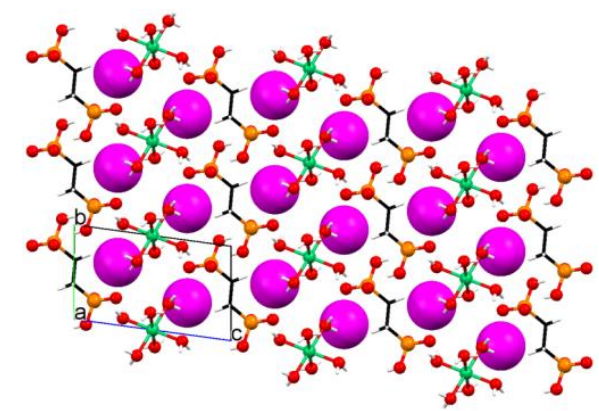

(c)

Figure 5. Crystal structure of Ni-EDPA: (a) View of the cation-anion pair; (b) The $\left[\mathrm{Ni}\left(\mathrm{H}_{2} \mathrm{O}\right)_{6}\right]^{2+}$ polyhedron; (c) Packing along the a axis. Lattice waters are shown as magenta spheres.

The structure of Ni-bpy-EDPA is different from the ones of other salts described thus far, in that the cationic portion of the salt is a cationic coordination polymer, composed of a cationic trans- $\left[\mathrm{Ni}\left(\mathrm{H}_{2} \mathrm{O}\right)_{4}\left(4,4^{\prime} \text {-bpy) }\right]^{2+}\right.$ unit, propagating along the $a b$ plane (Figure $6 \mathrm{a}, \mathrm{c}$ ). The $\mathrm{Ni}^{2+}$ center was coordinated by four water molecules at equatorial positions, whereas the axial positions are occupied by the $\mathrm{N}$ atom of the bridging $4,4^{\prime}$-bpy ligand (Figure $6 \mathrm{~b}$ ), leaving the dianionic $\mathbf{H}_{2} \mathbf{E D P A}^{2-}$ diphosphonate to play the role of the counterion for the cationic $1 \mathrm{D}$ chain. There is one lattice water molecule (Figure $6 \mathrm{c}$ ). The $\mathbf{H}_{\mathbf{2}}$ EDPA $^{2-}$ ligand moiety runs parallel to the $\mathrm{c}$ axis. There is a complex network of hydrogen bonds that involve the Ni-coordinated waters, the lattice water molecules, and the $-\mathrm{PO}_{3} \mathrm{H}^{-}$moieties. The structure of Ni-bpy-EDPA is reminiscent of that in the 1D nickel coordination polymer based on $\mathrm{P}, \mathrm{P}^{\prime}$-diphenylethylenediphosphinic acid and 4,4'-bipyridine [21]. 


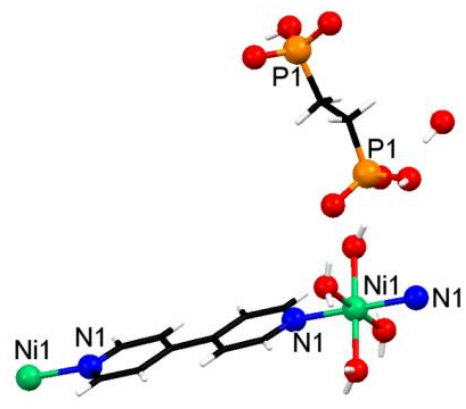

(a)

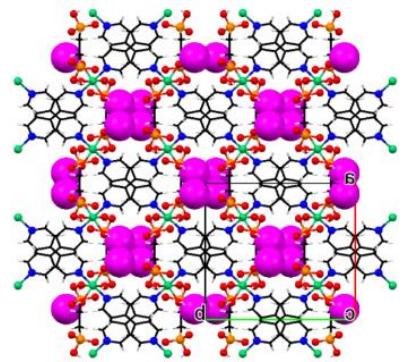

(c)

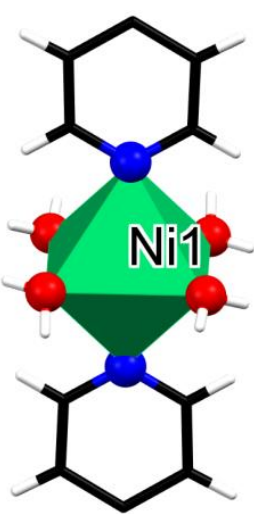

(b)

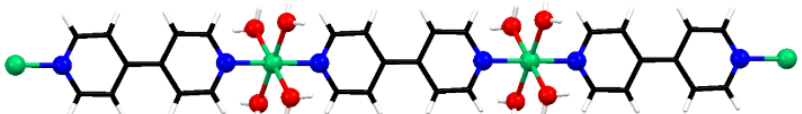

(d)

Figure 6. Crystal structure of Ni-4,4'-bpy-EDPA: (a) View of the cation-anion pair; (b) The $\left[\mathrm{Ni}\left(\mathrm{H}_{2} \mathrm{O}\right)_{4}\left(4,4^{\prime} \text {-bpy }\right)\right]^{2+}$ polyhedron; (c) Packing along the c axis. Lattice waters are shown as magenta spheres; $(\mathbf{d})$ Portion of the $1 \mathrm{D}$ " $\mathrm{Ni}\left(\mathrm{H}_{2} \mathrm{O}\right)_{4}-4,4$ '-bpy" chain.

\subsection{Computational Results: Total Electronic Densities and Partial Charges}

In order to visualise the electrostatic potential distribution around the molecular entities, the total electron densities were coloured with the Molecular Electrostatic Potential (MEP) value using the wxMacMolPlt software. All MEP surfaces were constructed using 80 Grid Points and a 0.1 max iso-value for the maps. The RGB surface colouration was used and the colour maps were inverted. The transparency was set to 50 and the surfaces were rendered as smooth and solid. After the energy minimisation of the molecular geometries the partial charges were calculated with Mulliken and Lowdin methods. For this study the partial charges on the phosphonic oxygen atoms are presented, since the oxygen atoms were considered as the coordination centers of the ligands. The mean values of the partial charges per oxygen atom were calculated for each method, and the $\%$ reduction of the partial charge was found using Equation (1):

$$
\%[\text { Charge Reduction }]=\frac{<\delta q_{\text {Non-EWG }}>-<\delta q_{E W G}>}{<\delta q_{\text {Non-EWG }}>} \times 100 \%
$$

The MEP surfaces and the partial charges of all studied phosphonate molecules are presented below in Table 2 and Figure 7.

From the results above, one can see that comparison of $\mathbf{B P A}^{2-}$ with either $\mathbf{H P A B P A}{ }^{1-}$ or $\left(\text { HPABPA }^{1-}\right)_{2}$ demonstrates the partial charge reduction for both Mulliken and Lowdin methods. The results also show that the formation of the dimer $\left(\mathbf{H P A B P A}^{1-}\right)_{2}$ from the monomer HPABPA ${ }^{1-}$ leads to even greater partial charge reduction, so the formation of the dimer results in lower electron density around the oxygen atoms and in lower probability for coordination to the metal ion. On the other hand, comparison of HEPA ${ }^{1-}$ with $\mathbf{H}_{2}$ EDPA $^{2-}$ demonstrates partial charge reduction for both Mulliken and Lowdin methods. Finally, by comparing EPA ${ }^{2-}$ with $\mathbf{H}_{2}$ EDPA $^{2-}$ a greater partial charge reduction is demonstrated by both methods and in lower probability for coordination to the metal ion. 
Table 2. B3LYP/PCM calculated partial charges on the oxygen atoms.

\begin{tabular}{|c|c|c|c|c|c|}
\hline \multicolumn{3}{|c|}{ HBPA $^{1-}$} & \multicolumn{3}{|c|}{$\mathrm{BPA}^{2-}$} \\
\hline Atom \# & 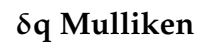 & $\delta q$ Lowdin & Atom \# & $\delta q$ Mulliken & $\delta q$ Lowdin \\
\hline 16 & -0.932911 & -0.884627 & 16 & -1.062429 & -0.999545 \\
\hline 17 & -0.969105 & -0.891882 & 17 & -1.064163 & -1.005116 \\
\hline 18 & -0.895888 & -0.796636 & 18 & -1.072408 & -0.986760 \\
\hline mean & -0.932635 & -0.857715 & mean & -1.066333 & -0.997140 \\
\hline \multicolumn{3}{|c|}{$\left(\mathrm{HPABPA}^{1-}\right)_{2}$} & \multicolumn{3}{|c|}{ HPABPA $^{1-}$} \\
\hline Atom \# & 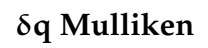 & $\delta q$ Lowdin & Atom \# & ઈq Mulliken & $\delta q$ Lowdin \\
\hline 2 & -1.011181 & -0.817501 & 15 & -1.024967 & -0.976540 \\
\hline 3 & -0.946950 & -0.905140 & 16 & -1.062499 & -0.994478 \\
\hline 4 & -0.982415 & -0.894151 & 17 & -1.050593 & -0.974468 \\
\hline 23 & -0.975002 & -0.898125 & & & \\
\hline 24 & -0.936067 & -0.911068 & & & \\
\hline 25 & -0.974519 & -0.821586 & & & \\
\hline mean & -0.971022 & -0.874595 & mean & -1.046020 & -0.981829 \\
\hline
\end{tabular}

\begin{tabular}{|c|c|c|}
\hline \multicolumn{3}{|c|}{$\mathrm{H}_{2} \mathrm{EDPA}^{2-}$} \\
\hline Atom \# & 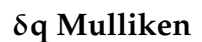 & $\delta q$ Lowdin \\
\hline 9 & -0.972095 & -0.893946 \\
\hline 10 & -0.961244 & -0.900770 \\
\hline 11 & -0.936159 & -0.814461 \\
\hline 13 & -0.974152 & -0.889730 \\
\hline 14 & -0.959120 & -0.811834 \\
\hline 16 & -0.956155 & -0.905960 \\
\hline mean & -0.959821 & -0.869450 \\
\hline
\end{tabular}

\begin{tabular}{|c|c|c|c|c|c|}
\hline \multicolumn{3}{|c|}{ HEPA $^{1-}$} & \multicolumn{3}{|c|}{ EPA $^{2-}$} \\
\hline Atom \# & ઈq Mulliken & $\delta q$ Lowdin & Atom \# & 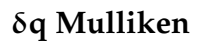 & $\delta q$ Lowdin \\
\hline 9 & -0.965273 & -0.893808 & 9 & -1.101121 & -1.004788 \\
\hline 10 & -0.964247 & -0.819322 & 10 & -1.103426 & -1.014740 \\
\hline 12 & -0.991020 & -0.907261 & 11 & -1.116413 & -1.012214 \\
\hline mean & -0.973513 & -0.873464 & mean & -1.106987 & -1.010581 \\
\hline
\end{tabular}

\begin{tabular}{|c|c|c|}
\hline \multirow[t]{2}{*}{ Molecules Pair } & \multicolumn{2}{|c|}{$\%$ Charge Reduction } \\
\hline & Mulliken & Lowdin \\
\hline HBPA $^{1-}$ - HPABPA ${ }^{1-}$ & $-12 \%$ & $-15 \%$ \\
\hline BPA $^{2-}$ - HPABPA ${ }^{1-}$ & $+2 \%$ & $+2 \%$ \\
\hline HBPA $^{1-}-\left(\mathrm{HPABPA}^{1-}\right)_{2}$ & $-4 \%$ & $-2 \%$ \\
\hline $\mathrm{BPA}^{2-}-\left(\mathrm{HPABPA}^{1-}\right)_{2}$ & $+9 \%$ & $+12 \%$ \\
\hline HPABPA $^{1-}-\left(\text { HPABPA }^{1-}\right)_{2}$ & $+7 \%$ & $+11 \%$ \\
\hline HEPA $^{1-}-\mathrm{H}_{2}$ EDPA $^{2-}$ & $+1 \%$ & $+1 \%$ \\
\hline $\mathrm{EPA}^{2-}-\mathrm{H}_{2} \mathrm{EDPA}^{2-}$ & $+13 \%$ & $+14 \%$ \\
\hline
\end{tabular}




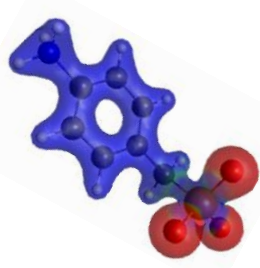

(a)

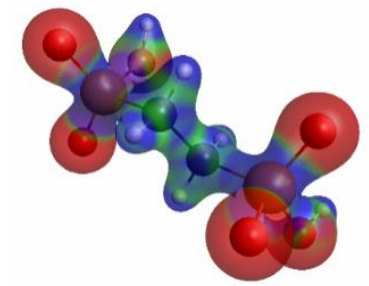

(e)

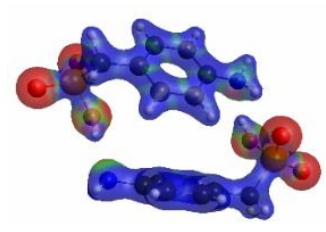

(b)

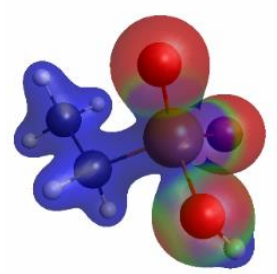

(f)

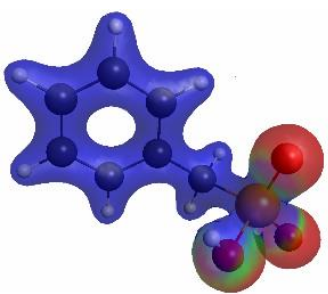

(c)

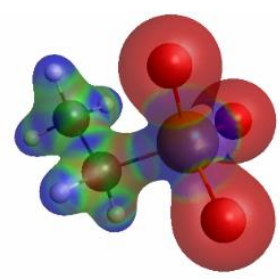

(g)

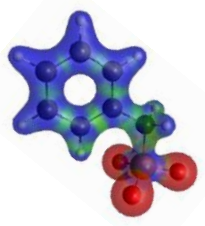

(d)

Figure 7. DFT calculated total electron density colored with the Electrostatic Potential Map value for a) $\mathrm{HBPA}^{1-}$, b) $\left(\mathrm{HPABPA}^{1-}\right)_{2}$, c) $\mathrm{HPABPA}^{1-}$ d) $\mathrm{BPA}^{2-}$ e) $\mathrm{H}_{2} \mathrm{EDPA}^{2-}$, f) $\mathrm{HEPA}^{1-}$, and g) $\mathrm{EPA}^{2-}$, at the B3LYP/PCM geometry.

\section{Discussion}

It is common in metal phosphonate chemistry to seek for MOFs, coordination polymers, and networks that represent new and exciting structures in which the metal-phosphonate bonds play a key role. However, there is a class of metal phosphonate compounds (salts) where the deprotonated (anionic) phosphonate plays the role of the counterion to a cationic metal complex, or to a cationic coordination polymer. Such non-coordinating systems are useful in modeling phosphonate compounds in biological [53], polymeric, [54], or hydrogel matrices [6,55].

In the ionic metal phosphonates presented herein, there are two major structural features that draw attention: (a) the cationic metal center and its coordination environment, and (b) the deprotonated anionic phosphonate. The metal cation is bound by aqua ligands (solvent), and occasionally, by other, externally-added ligands (4, $4^{\prime}$-bpy in this case for Ni-bpy-EDPA). As reported before, there is a correlation between the ionic radius of the metal ion and the bond distances between the metal and the ligand atoms coordinated to the metal center [2,56-58]. Since there is no direct metal-phosphonate bonding in the compounds reported herein, the only correlations that can be drawn are those for metal- $\mathrm{O}_{\text {water }}$ bonds. By calculating the average metal- $\mathrm{O}_{\text {water }}$ bond lengths, an increasing trend can be observed, see Figure 8.

Metal- $\mathrm{O}_{\text {water }}$ bond lengths for the divalent metal ions $\mathrm{Zn}$ [18], Ba [58], and Co [12] were taken from literature sources, whereas those for $\mathrm{Mg}, \mathrm{Ni}, \mathrm{Ca}$ and $\mathrm{Sr}$ were taken from the structures described in the present paper.

The phosphonate anion is invariably stabilized by hydrogen bonds. For the "simple" system Ni-EDPA (i.e., the phosphonate ligand contains only phosphonate groups, without other ligands present) the $\mathbf{H}_{2}$ EDPA $^{2-}$ dianion interacts with a total of 16 hydrogen bonds (with neighboring $\mathbf{H}_{2}$ EDPA $^{2-}$ dianions and water molecules). Similar observations can be made for the system Ni-bpy-EDPA. The HPABPA ${ }^{-}$ligand possesses a doubly-deprotonated phosphonate group, but a protonated amine group. The $-\mathrm{PO}_{3}{ }^{2-}$ moiety in the isostructural compounds Ca-PABPA and Sr-PABPA participates in seven hydrogen bonds, whereas the $-\mathrm{NH}_{3}{ }^{+}$moiety participates in three. In the structure of Mg-PABPA, where there are also lattice waters, the $-\mathrm{PO}_{3}{ }^{2-}$ moiety participates in five hydrogen bonds, whereas the $-\mathrm{NH}_{3}{ }^{+}$moiety participates in three. Here, the lattice and $\mathrm{Mg}$-coordinated waters form a multitude of hydrogen bonding interactions. Finally, in the Mg-TDTMP salt, the four phosphonate groups, overall, participate in twenty one hydrogen bonds, and each protonated tertiary 
amine group, in one. In general, it has been observed that the higher the coordination state of the phosphonate ligand, the lower is the extent of hydrogen bonding [2].

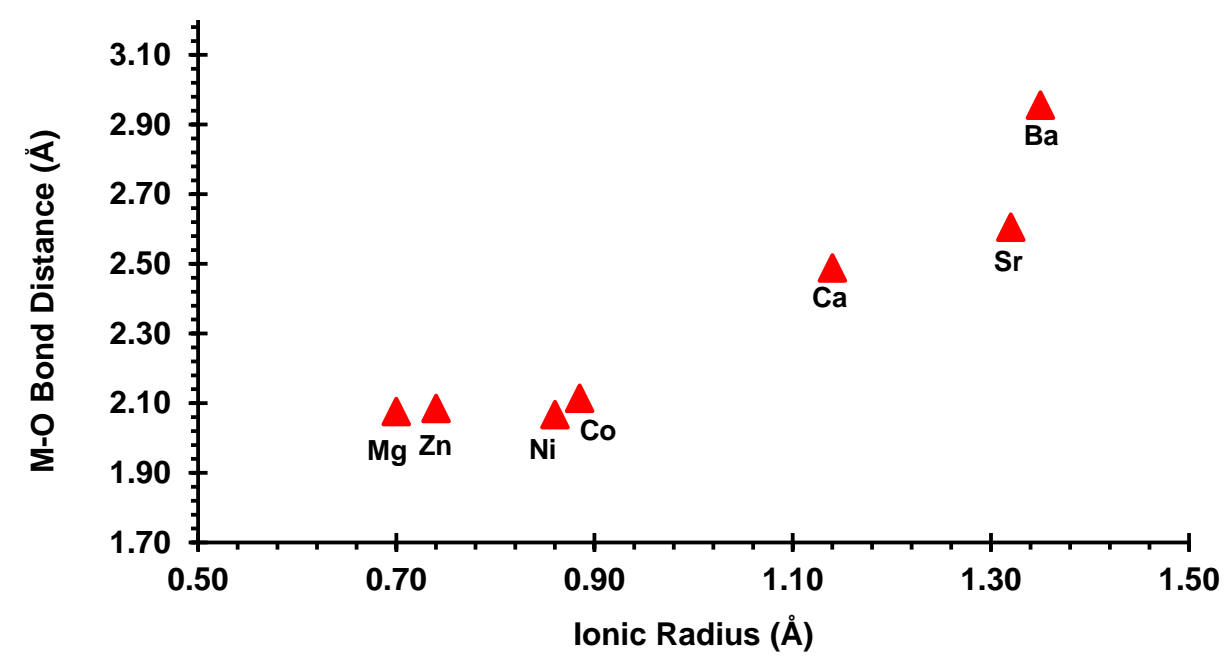

Figure 8. Dependence of $\mathrm{M}-\mathrm{O}\left(\mathrm{H}_{2} \mathrm{O}\right)$ bond lengths in divalent metal-aqua species on metal ionic radius.

\section{Conclusions}

Herein, we presented a family of metal phosphonate-based inorganic-organic salts, which share a common characteristic, i.e., the phosphonate anion is not coordinated to a metal center, but merely plays the role of the counter-anion. In contrast to the majority of metal phosphonate materials reported in the literature, in which the phosphonate ligand was found coordinated to the metal center, the compounds Mg-PABPA, Ca-PABPA, Sr-PABPA, Ni-EDPA, Mg-TDTMP, and Ni-bpy-EDPA contained the metal center as a hydrated complex, except Ni-bpy-EDPA, which contained the $\mathrm{Ni}^{2+}$ center as part of a coordination polymer with the 4,4'-bpy bridging ligand. The formation of these "platonic" compounds can be explained based on the high affinity of the $\mathrm{M}^{2+}$ metal ions for water as a ligand (or for 4,4'-bpy) and the reduced affinity of the phosphonate ligand, particularly in the case of $\mathbf{H}_{\mathbf{2}} \mathbf{P A B P A}$, for the metal centers. Another factor that plays a role in the stabilization of such compounds in the solid state is the multitude of hydrogen bonding interactions that occur, due to the plethora of hydrogen bonding donors and acceptors. Hence, these compounds could be attractive for applications such as proton conductivity, and such studies are currently under way in our laboratories.

Although the main focus in metal phosphonate chemistry is the synthesis and exploration of coordination polymers [59], the class of ionic phosphonates (either with metal complexes, or organic counter-cations) could potentially unlock new potential in this research area. Given the plethora of structurally diverse (poly)phosphonate $[60,61]$ and "mixed" phosphonate (e.g. with carboxy- [56], sulfono- [62], amino- [63], or N-heterocyclic groups [64]) ligands available, one could envision countless possibilities in the synthesis, fabrication and properties of such solids [65].

Supplementary Materials: The following are available online at http://www.mdpi.com/2073-4352/9/6/301/s1, Figures S1-S5: Calculated and measured powder XRD diagrams for all compounds; Figure S6: ATR-IR spectra of all metal phosphonate compounds and "free" ligands; Figures S7-S11: TGA and DSC traces for all compounds; Crystallographic Information Files (six cif files) for all compounds.

Author Contributions: conceptualization, K.D.D.; software, K.X.; validation, K.X.; investigation, Z.A., S.C., D.C.-L., G.M., J.Z, and J.Z.; writing—original draft preparation, K.D.D.; writing-review and editing, all authors; supervision, K.D.D.

Funding: K.D.D. acknowledges the Research Committee of the University of Crete (Grant KA 10329) for financial support.

Acknowledgments: We thank Prof. Aurelio Cabeza (Universidad de Malaga, Spain) for technical support.

Conflicts of Interest: The authors declare no conflict of interest. 


\section{References}

1. Clearfield, A.; Demadis, K.D. Metal Phosphonate Chemistry: From Synthesis to Applications; Royal Society of Chemistry: London, UK, 2012.

2. Demadis, K.D.; Stavgianoudaki, N. Structural diversity in metal phosphonate frameworks: Impact on applications. In Metal Phosphonate Chemistry: From Synthesis to Applications; Clearfield, A., Demadis, K.D., Eds.; Royal Society of Chemistry: London, UK, 2012; Chapter 14; pp. 438-492.

3. Zareba, J.K. Tetraphenylmethane and tetraphenylsilane as building units of coordination polymers and supramolecular networks-A focus on tetraphosphonates. Inorg. Chem. Commun. 2017, 86, 172-186. [CrossRef]

4. Bao, S.-S.; Shimizu, G.K.H.; Zheng, L.-M. Proton conductive metal phosphonate frameworks. Coord. Chem. Rev. 2019, 378, 577-594. [CrossRef]

5. Groves, J.A.; Miller, S.R.; Warrender, S.J.; Mellot-Draznieks, C.; Lightfoot, P.; Wright, P.A. The first route to large pore metal phosphonates. Chem. Commun. 2006, 31, 3305-3307. [CrossRef] [PubMed]

6. Papathanasiou, K.E.; Vassaki, M.; Spinthaki, A.; Alatzoglou, F.-E.G.; Tripodianos, E.; Turhanen, P.; Demadis, K.D. Phosphorus chemistry: From small molecules to polymers to pharmaceutical and industrial applications. Pure Appl. Chem. 2019, 91, 421-441. [CrossRef]

7. Shah, B.; Chudasama, U. Application of zirconium phosphonate-a novel hybrid material as an ion exchanger. Des. Wat. Treat. 2012, 38, 227-235.

8. Armakola, E.; Colodrero, R.M.P.; Bazaga-García, M.; Salcedo, I.R.; Choquesillo-Lazarte, D.; Cabeza, A.; Kirillova, M.V.; Kirillov, A.M.; Demadis, K.D. Three-component copper-phosphonate-auxiliary ligand systems: Proton conductors and efficient catalysts in mild oxidative functionalization of cycloalkanes. Inorg. Chem. 2018, 57, 10656-10666. [CrossRef] [PubMed]

9. Moschona, A.; Plesu, N.; Mezei, G.; Thomas, A.; Demadis, K.D. Corrosion protection of carbon steel by tetraphosphonates of systematically different molecular size. Corr. Sci. 2018, 145, 135-150. [CrossRef]

10. Gałezowska, J.; Kafarski, P.; Kozłowski, H.; Młynarz, P.; Nurchi, V.M.; Pivetta, T. $\mathrm{N}, \mathrm{N}^{\prime}$-ethylenediaminobis(benzylphosphonic acids) as a potent class of chelators for metal ions. Inorg. Chim. Acta 2009, 362, 707-713. [CrossRef]

11. Heering, C.; Nateghi, B.; Janiak, C. Charge-assisted hydrogen-bonded networks of $\mathrm{NH}_{4}{ }^{+}$and $\left[\mathrm{Co}\left(\mathrm{NH}_{3}\right)_{6}\right]^{3+}$ with the new linker anion of 4-phosphono-biphenyl-4'-carboxylic acid. Crystals 2016, 6, 22. [CrossRef]

12. Wilk, M.; Janczak, J.; Videnova-Adrabinska, V. Hexaaquacobalt(II) bis[hydrogen bis(4-carboxyphenylphosphonate)] dihydrate. Acta Crystallogr. Sect. C-Cryst. Struct. Commun. 2011, 67, 9-12. [CrossRef]

13. Gholivand, K.; Farrokhi, A.R. Supramolecular hydrogen-bonded frameworks from a new bisphosphonic Acid and transition metal ions. Z. Anorg. Allg. Chem. 2011, 637, 263-268. [CrossRef]

14. Sergienko, V.S.; Aleksandrov, G.G.; Afonin, E.G. An unusual function of the anion of 1-hydroxyethane-1,1-diphosphonic acid $\left(\mathrm{H}_{4} \mathrm{~L}\right)$ : Crystal structure of $\left[\mathrm{Ni}(\mathrm{phen})_{3}\right]\left(\mathrm{H}_{7} \mathrm{~L}_{2}\right)_{0.5}\left(\mathrm{H}_{5} \mathrm{~L}_{2}\right)_{0.5} \cdot 2 \mathrm{H}_{2} \mathrm{O}$. Cryst. Rep. 2000, 45, 432-438. [CrossRef]

15. Yang, J.; Ma, J.-F.; Zheng, G.-L.; Li, L.; Li, F.-F.; Zhang, Y.-M.; Liu, J.-F. Divalent transition metal phosphonates with new structure containing hydrogen-bonded layers of phosphonate anions. J. Solid State Chem. 2003, 174, 116-124. [CrossRef]

16. Latham, K.; Coyle, A.M.; Rix, C.J.; Fowless, A.; White, J.M. Effect of ring substituents on crystal packing and H-bonding in a series of halobis(phen)copper(II) arylphosphonic acid complexes. Polyhedron 2007, 26, 222-236. [CrossRef]

17. Ma, K.-R.; Wei, C.-L.; Zhang, Y.; Kan, Y.-H.; Cong, M.-H.; Yang, X.-J. Structures and spectroscopy studies of two M(II)-phosphonate coordination polymers based on alkaline earth metals ( $\mathrm{M}=\mathrm{Ba}, \mathrm{Mg})$. J. Spectroscopy 2013, 2013. [CrossRef]

18. Demadis, K.D.; Barouda, E.; Zhao, H.; Raptis, R.G. Structural architectures of charge-assisted,

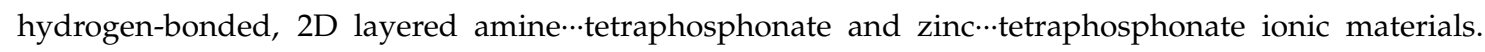
Polyhedron 2009, 28, 3361-3367. [CrossRef]

19. Murugavel, R.; Kuppuswamy, S.; Randoll, S. Cooperative binding of phosphate anion and a neutral nitrogen donor to alkaline-earth metal ions. Investigation of Group 2 metal-organophosphate interaction in the absence and presence of 1,10-phenanthroline. Inorg. Chem. 2008, 47, 6028-6039. [CrossRef] 
20. Lee, B.H.; Lynch, V.M.; Cao, G.; Mallouk, T.E. Structure of $\left[\mathrm{Mg}\left\{\mathrm{HO}_{3} \mathrm{PCH}\left(\mathrm{C}_{6} \mathrm{H}_{5}\right)_{2}\right\}_{2}\right] \cdot 8 \mathrm{H}_{2} \mathrm{O}$, a layered phosphonate salt. Acta Cryst. 1988, C44, 365-367.

21. Guerri, A.; Taddei, M.; Bataille, T.; Moneti, S.; Boulon, M.-E.; Sangregorio, C.; Costantino, F.; Ienco, A. Same not the same: Thermally driven transformation of nickel phosphinate-bipyridine one-dimensional chains into three-dimensional coordination polymers. Cryst. Growth Des. 2018, 18, 2234-2242. [CrossRef]

22. Schier, A.; Gamper, S.; Müller, G. Synthesis and crystal structure of magnesium bis[2-aminoethyl(hydrogen)phosphonate] octahydrate, $\mathrm{Mg}(2-\mathrm{AEPH})_{2} \cdot 8 \mathrm{H}_{2} \mathrm{O}$. Inorg. Chim. Acta 1990, 177, 179-183. [CrossRef]

23. Smith, G.; Wermuth, U.D. The coordination complex structures and hydrogen bonding in the three-dimensional alkaline earth metal salts $(\mathrm{Mg}, \mathrm{Ca}, \mathrm{Sr}$ and $\mathrm{Ba})$ of (4-aminophenyl)arsonic acid. Acta Cryst. 2017, C73, 61-67. [CrossRef] [PubMed]

24. Nguyen, T.V.; Bekensir, A. Aromatic cation activation: Nucleophilic substitution of alcohols and carboxylic acids. Org. Lett. 2014, 16, 1720-1723. [CrossRef] [PubMed]

25. Taylor, S.D.; Kotoris, C.C.; Dinaut, A.N.; Chen, M.-J. Synthesis of aryl(difluoromethylenephosphonates) via electrophilic fluorination of $\alpha$-carbanions of benzylic phosphonates with $\mathrm{N}$-fluorobenzenesulfonimide. Tetrahedron 1998, 54, 1691-1714. [CrossRef]

26. Penicaud, V.; Maillet, C.; Janvier, P.; Pipelier, M.; Bujoli, B. New water-soluble diamine complexes as catalysts for the hydrogenation of ketones under hydrogen pressure. Eur. J. Org. Chem. 1999, 7, 1745-1748.

27. Wydysh, E.A.; Medghalchi, S.M.; Vadlamudi, A.; Townsendd, C.A. Design and synthesis of small molecule glycerol 3-phosphate acyltransferase inhibitors. J. Med. Chem. 2009, 52, 3317-3327. [CrossRef] [PubMed]

28. APEX3, V2018.7-2; Bruker AXS, Inc.: Madison, WI, USA, 2018.

29. Sheldrick, G.M. A short history of SHELX. Acta Cryst. 2008, A64, 339-341.

30. Sheldrick, G.M. Crystal structure refinement with SHELXL. Acta Cryst. 2015, C71, 3-8.

31. APEX2 v2014.9-0; Bruker AXS Inc.: Madison, WI, USA, 2014.

32. Kohn, W.; Sham, L.J. Self-consistent equations including exchange and correlation effects. Phys. Rev. 1965, 140, A1133-A1138. [CrossRef]

33. Becke, A.D. Density-functional thermochemistry. III. The role of exact exchange. J. Chem. Phys. 1993, 98, 5648-5653. [CrossRef]

34. King, H.F.; Dupuis, M. Numerical integration using rys polynomials. J. Comput. Phys. 1976, 21, $144-165$. [CrossRef]

35. Hariharan, P.C.; Pople, J.A. The influence of polarization functions on molecular orbital hydrogenation energies. Theoret. Chim. Acta 1973, 28, 213-222. [CrossRef]

36. Mulliken, R.S. Electronic population analysis on LCAO-MO molecular wave functions. Parts 1-4. J. Chem. Phys. 1955, 23, 1833-1840, 1841-1846, 2338-2342, and 2343-2346. [CrossRef]

37. Lowdin, P.-O. On the orthogonality problem. Adv. Chem. Phys. 1970, 5, 185-199.

38. Li,H.; Pomelli, C.; Jensen, J.H. Continuum solvation of large molecules described by QM/MM: A semi-iterative implementation of the PCM/EFP interface. J. Theor. Chem. Acc. 2003, 109, 71-84. [CrossRef]

39. Schmidt, M.W.; Baldridge, K.K.; Boatz, J.A.; Elbert, S.T.; Gordon, M.S.; Jensen, J.H.; Koseki, S.; Matsunaga, N.; Nguyen, K.A.; Su, S.; et al. General atomic and molecular electronic structure system. J. Comput. Chem. 1993, 14, 1347-1363. [CrossRef]

40. Gordon, M.S.; Schmidt, M.W. Advances in electronic structure theory: GAMESS a decade later. In Theory and Applications of Computational Chemistry, the First Forty Years; Dykstra, C.E., Frenking, G., Kim, K.S., Scuseria, G.E., Eds.; Elsevier: Amsterdam, The Netherland, 2005; Chapter 41; pp. 1167-1189.

41. Bode, B.M.; Gordon, M.S. MacMolPlt: a graphical user interface for GAMESS. J. Mol. Graphics Mod. 1998, 16, 133-138. [CrossRef]

42. Hanwell, M.D.; Curtis, D.E.; Lonie, D.C.; Vandermeersch, T.; Zurek, E.; Hutchison, G.R. Avogadro: an advanced semantic chemical editor, visualization, and analysis platform. J. Cheminform. 2012, 4, 17. [CrossRef] [PubMed]

43. Rappe, A.K.; Casewit, C.J.; Colwell, K.S.; Goddard III, W.A.; Skiff, W.M. UFF, a full periodic table force field for molecular mechanics and molecular dynamics simulations. J. Am. Chem. Soc. 1992, 114, 10024-10035. [CrossRef]

44. Baker, J. An algorithm for the location of transition states. J. Comput. Chem. 1986, 7, 385-395. [CrossRef] 
45. Helgaker, T. Transition-state optimizations by trust-region image minimization. Chem. Phys. Lett. 1991, 182, 503-510. [CrossRef]

46. Culot, P.; Dive, G.; Nguyen, V.H.; Ghuysen, J.M. A quasi-Newton algorithm for first-order saddle-point location. Theoret. Chim. Acta 1992, 82, 189-205. [CrossRef]

47. Halgren, T.A. Merck molecular force field. I. Basis, form, scope, parameterization, and performance of MMFF94. J. Comput. Chem. 1996, 17, 490-519. [CrossRef]

48. Demadis, K.D.; Papadaki, M.; Raptis, R.G.; Zhao, H. Corrugated, sheet-like architectures in layered alkaline earth metal R,S-hydroxyphosphonoacetate frameworks: Applications for anti-corrosion protection of metal surfaces. Chem. Mater. 2008, 20, 4835-4846. [CrossRef]

49. Lodhia, S.; Turner, A.; Papadaki, M.; Demadis, K.D.; Hix, G.B. Polymorphism, composition and structural variability in topology in 1D, 2D and 3D copper phosphonocarboxylate materials. Cryst. Growth Des. 2009, 9, 1811-1822. [CrossRef]

50. Ruiz-Agudo, E.; Rodriguez-Navarro, C.; Sebastian-Pardo, E. Sodium sulfate crystallization in the presence of phosphonates: Implications in ornamental stone conservation. Cryst. Growth Des. 2006, 6, 1575-1583. [CrossRef]

51. Demadis, K.D.; Anagnostou, Z.; Panera, A.; Mezei, G.; Kirillova, M.V.; Kirillov, A.M. Three-Component 1D and 2D metal phosphonates: Structural variability, topological analysis and catalytic hydrocarboxylation of alkanes. RSC-Adv. 2017, 7, 17788-17799. [CrossRef]

52. Demadis, K.D.; Armakola, E.; Papathanasiou, K.E.; Mezei, G.; Kirillov, A.M. Structural systematics and topological analysis of coordination polymers with divalent metals and a glycine-derived tripodal phosphonocarboxylate. Cryst. Growth Des. 2014, 14, 5234-5243. [CrossRef]

53. Papathanasiou, K.E.; Demadis, K.D. Phosphonates in matrices. In Tailored Organic-Inorganic Materials; Brunet, E., Clearfield, A., Colon, J.L., Eds.; John Wiley \& Sons Inc.: New York, NY, USA, 2015; Chapter 3; pp. 83-135.

54. Demadis, K.D.; Theodorou, I.; Paspalaki, M. Controlled release of bis-phosphonate pharmaceuticals from cationic biodegradable polymeric matrices. Ind. Eng. Chem. Res. 2011, 50, 5873-5876. [CrossRef]

55. Papathanasiou, K.E.; Turhanen, P.; Brückner, S.I.; Brunner, E.; Demadis, K.D. Smart, programmable and responsive injectable hydrogels for controlled release of cargo osteoporosis drugs. Sci. Rep. $2017,7$. [CrossRef]

56. Bazaga-García, M.; Papadaki, M.; Colodrero, R.M.P.; Olivera-Pastor, P.; Losilla, E.R.; Nieto-Ortega, B.; Aranda, M.A.G.; Choquesillo-Lazarte, D.; Cabeza, A.; Demadis, K.D. Tuning proton conductivity in alkali metal phosphonocarboxylates by cation size-induced and water-facilitated proton transfer pathways. Chem. Mater. 2015, 27, 424-435. [CrossRef]

57. Salcedo, I.R.; Colodrero, R.M.P.; Bazaga-García, M.; Vasileiou, A.; Papadaki, M.; Olivera-Pastor, P.; Infantes-Molina, A.; Losilla, E.R.; Mezei, G.; Cabeza, A.; et al. From light to heavy alkali metal tetraphosphonates $(\mathrm{M}=\mathrm{Li}, \mathrm{Na}, \mathrm{K}, \mathrm{Rb}, \mathrm{Cs})$ : Cation size-induced structural diversity and water-facilitated proton conductivity. CrystEngComm 2018, 20, 7648-7658. [CrossRef]

58. Demadis, K.D.; Katarachia, S.D.; Zhao, H.; Raptis, R.G.; Baran, P. Alkaline earth metal organotriphosphonates: Inorganic-organic polymeric hybrids from dication-dianion association. Cryst. Growth Des. 2006, 6, 836-838. [CrossRef]

59. Zorlu, Y.; Erbahar, D.; Çetinkaya, A.; Bulut, A.; Erkal, T.S.; Yazaydin, A.O.; Beckmann, J.; Yücesan, G. A cobalt arylphosphonate MOF - superior stability, sorption and magnetism. Chem. Commun. 2019, 55, 3053-3056. [CrossRef]

60. Yücesan, G.; Zorlu, Y.; Stricker, M.; Beckmann, J. Metal-organic solids derived from arylphosphonic acids. Coord. Chem. Rev. 2018, 369, 105-122. [CrossRef]

61. Silvestre, J.-P.; Dao, N.Q.; Leroux, Y. A survey of the behavior of the hydroxybisphosphonic function in crystallized acids, metallic salts, and some related compounds. Heteroatom Chem. 2001, 12, 73-89. [CrossRef]

62. Beyer, O.; Homburg, T.; Albat, M.; Stock, N.; Lüning, U. Synthesis of phosphonosulfonic acid building blocks as linkers for coordination polymers. New J. Chem. 2017, 41, 8870-8876. [CrossRef]

63. Schmidt, C.; Feyand, M.; Rothkirch, A.; Stock, N. High-throughput and in situ EDXRD investigation on the formation of two new metal aminoethylphosphonates- $\mathrm{Ca}\left(\mathrm{O}_{3} \mathrm{PC}_{2} \mathrm{H}_{4} \mathrm{NH}_{2}\right)$ and $\mathrm{Ca}(\mathrm{OH})\left(\mathrm{O}_{3} \mathrm{PC}_{2} \mathrm{H}_{4} \mathrm{NH}_{3}\right) \cdot 2 \mathrm{H}_{2} \mathrm{O}$. J. Solid State Chem. 2012, 188, 44-49. [CrossRef] 
64. Gałęzowska, J.; Czapor-Irzabek, H.; Janicki, R.; Chmielewska, E.; Janek, T. New aspects of coordination chemistry and biological activity of NTMP-related diphosphonates containing a heterocyclic ring. New J. Chem. 2017, 41, 10731-10741. [CrossRef]

65. Shearan, S.; Stock, N.; Emmerling, F.; Demel, J.; Wright, P.A.; Demadis, K.D.; Vassaki, M.; Costantino, F.; Vivani, R.; Sallard, S.; et al. New directions in metal phosphonate and phosphinate chemistry. Crystals 2019, 9, 270. [CrossRef] 